\title{
ESTRATEGIAS DE ADAPTACIÓN Y MEDIOS DE VIDA DE LAS FAMILIAS INTEGRANTES DE LA FUNDACIÓN CONSEJO VEREDAL -FCV-, MUNICIPIO DE CALARCÁ, QUINDÍO
}

\author{
Yuli Marín López ${ }^{1}$ \\ Carlos Gilberto Bedoya Patiño ${ }^{2}$ \\ Gloria Inés Cárdenas Grajales ${ }^{3}$
}

Recibido el 26 de marzo de 2014, aprobado el 9 de octubre de 2014 y actualizado el 30 de abril de 2015

DOI: 10.17151/luaz.2015.41.12

\section{RESUMEN}

Este artículo presenta la estructura de estrategias de vida de la organización campesina Fundación Consejo Veredal ubicada en la vereda Travesías, municipio de Calarcá, en ella se llevó a cabo un estudio con nueve familias beneficiarias del proceso de reforma agraria Ley 160 de 1994 que tuvo como objetivo la identificación de las estrategias de vida de los hogares y las restricciones que impiden el éxito de estas estrategias. El estudio se realizó mediante la caracterización de los sistemas de producción y la identificación de los medios de vida que despliegan las familias para su supervivencia. Se utilizó la metodología de Enfoque de Medios de Vida del DFID Department for International Development- a través de la cual se valoraron los capitales: Humano, Social, Natural, Físico y Financiero por medio de la medición de 17 indicadores pertenecientes a cinco capitales. Los resultados del estudio permitieron la identificación de los medios de vida utilizados por esta comunidad para adaptarse a las nuevas dinámicas generadas por los efectos de la globalización en el sector rural en economías campesinas y particularmente por la crisis cafetera. Se logró la identificación de estrategias que implementan las familias con el fin de generar ingresos y mejores condiciones de vida, así como las interacciones que se establecen entre estas y fenómenos sociales como: la pobreza, el origen y distribución de los ingresos, las políticas para la diversificación, diversificación vs. agricultura, organización social, educación y acceso a mercados. Los resultados del estudio muestran que los capitales de mayor valoración fueron el Humano con una media de 4,16 y el Físico con una media de 4,04. Los capitales con menor valoración fueron el Social con una media de 3,09 y el Financiero con una media de 3,29 . El Capital Natural se ubica en un rango medio con 3,56.

\section{PALABRAS CLAVE}

Medios de vida, estrategias de adaptación, capital humano, capital social, capital natural, capital físico, capital financiero, economía campesina. 


\title{
ADAPTATION STRATEGIES AND LIVELIHOOD OF FAMILIES MAKING UP THE VILLAGE FOUNDATION COUNCIL -VFC- MUNICIPALITY OF CALARCÁ, QUINDÍO
}

\begin{abstract}
This article presents the structure of living strategies of the rural organization "Village Foundation Council" located in the Travesías village, municipality of Calarcá, where a study with nine families beneficiary of the process of the agrarian reformation Law 160 of 1994 took place which had as objective the identification of living strategies of the homes and the restrictions which inhibit the success of these strategies. The study was carried out through the characterization of the production systems and the identification of livelihood families display for their survival. The DFID -Department for International DevelopmentLivehood Focus methodology was used to value the human, social, natural, physical and financial capitals by means of the measurement of 17 indicators belonging to five capitals. The results of the study allowed the identification of the ways of livelihood used by this community to adapt to the new dynamics generated by the effects of globalization in the rural sector in peasant economy and particularly because of the coffee growers crisis. It was possible to achieve the identification of strategies that the families implement in order to generate income and better living conditions as well as the interactions that exist between these and social phenomena such as poverty, origin and distribution of incomes, policies for diversification, diversification vs. agriculture, social organization, education and access to markets. The results of the study, shows that the capitals with higher evaluation were the social with a 4.16 average and Physical with a 4.04. average The capitals with lower evaluation were the Social with a 3.09 average and the financial with a 3.29 average. The natural capital is located in a middle range with 3.56 .
\end{abstract}

\section{KEY WORDS}

Livelihood, coping strategies, human capital, human capital, natural capital, physical capital, financial capital, peasant economy.

\section{INTRODUCCIÓN}

El Enfoque de Medios de Vida nació a finales de la década de 1980, como respuesta a la necesidad de contar con un marco propicio para el análisis integral de las estrategias de vida de los hogares rurales [Chambers y Conway (1991), Bebbington (1999), DFID (1999) y WFP (2001) citados por Stoin y Donovan (2010)].

Un medio de vida comprende posibilidades, activos (incluyendo recursos tanto materiales como sociales) y actividades necesarias para 
ganarse la vida. Un medio de vida es sostenible cuando puede soportar tensiones y choques y recuperarse de los mismos, y a la vez mantener y mejorar sus posibilidades y activos, tanto en el presente como en el futuro, sin dañar la base de los recursos naturales existentes. (Miranda, 2003, p. 35)

De acuerdo con Stoin y Donovan (2010) el Enfoque de Medios de Vida sirve no solo para la formulación, ejecución y evaluación de proyectos e intervenciones de desarrollo, sino también para la investigación. A diferencia de otros enfoques convencionales que a menudo se concentran en los sistemas productivos o fincas, el "Enfoque de Medios de Vida parte del hogar como unidad socioeconómica y analítica, determinando su dotación con las siguientes cinco formas de capital o activos de medios de vida: Capital Humano, Capital Social, Capital Natural, Capital Físico y Capital Financiero" (DFID, 1999).

Los grandes cambios originados en el sector rural a finales del siglo XX y comienzos del siglo XXI, como consecuencia del Modelo Agroexportador han ocasionado que comunidades campesinas que tradicionalmente se habían ocupado de la producción cafetera en la zona del Ilamado Eje Cafetero, hoy, ante la grave crisis del cultivo y el gremio que lo representa, hayan tenido la necesidad de diversificar su portafolio de ingresos, y con él las estrategias de supervivencia optando por actividades complementarias a las producción cafetera que les permita disminuir la vulnerabilidad en la que se encuentran.

Las estrategias de supervivencia por las que han optado los hogares de economía campesina en la zona cafetera son diversas y van desde el trabajo asalariado hasta procesos de migración interna y externa. Ello ha generado nuevas dinámicas relacionadas con la supervivencia de las familias, las cuales dependen cada vez más del buen uso que puedan hacer de sus activos (humano, social, natural, físico y financiero), de la diversificación de las actividades productivas, del portafolio de servicios, de la conservación del medio ambiente, de la distribución de los ingresos y de la participación y organización para la toma de decisiones que incidan sobre las políticas públicas y la gestión de los recursos naturales de sus territorios.

El presente estudio se enfocó en la identificación y análisis de los medios y estrategias de vida que han desarrollado los hogares de la Fundación Consejo Veredal (FCV) para su sostenimiento como alternativa para permanecer en el campo y no abandonar la actividad agropecuaria; también permitió configurar una visión amplia y documentada acerca de las oportunidades y obstáculos que caracteriza la vida de las personas de esta comunidad y que les ha permitido hacer frente a la actual crisis del sector agropecuario en general y de la caficultura en particular.

En el año 1997 los nueve hogares que conforman la FCV obtuvieron el beneficio de tener acceso a tierra como propietarios. Se empieza a generar un proceso de adaptación a 
un contexto rural vulnerable, con pocos ingresos económicos con los que se cubrían las necesidades básicas y generaban procesos productivos.

En este contexto, algunas familias conforman un Consejo Veredal con el fin de identificar las necesidades de la comunidad, participar y actuar ante los conflictos, y buscar su fortalecimiento en la búsqueda de iniciativas para un desarrollo endógeno. En el año 2009 el Consejo Veredal se constituye en la FCV y empieza una búsqueda legal en el proceso de transformación de las realidades sociopolíticas del territorio a través de mecanismos solidarios que permitieron el manejo del mismo por medio de redes sociales incluyentes teniendo como base la economía campesina ${ }^{4}$.

En la actualidad la mayoría de los pequeños productores y campesinos de estos hogares trabajan sin condiciones ni apoyo estatal, viéndose en la necesidad de buscar alternativas y estrategias para mejorar las condiciones y la calidad de vida de sus familias. Desde esta perspectiva, la comunidad ha ido modificando su portafolio de ingresos y por consiguiente diversificando sus medios de vida, adaptando la economía campesina a las nuevas condiciones de la llamada multifuncionalidad a las que le abre paso necesariamente la crisis del café y la búsqueda de esta organización de base campesina por configurar espacios de inclusión y autonomía que les permita acceder a los beneficios de condiciones económicas más ventajosas por medio de estrategias de adaptación, en las que sus activos puedan hacerse más productivos.

\section{MATERIALES Y MÉTODOS}

\section{Localización}

El estudio se llevó a cabo con nueve hogares campesinos de las fincas: El Triángulo, El Milagro, La Favorita, El Oso, Vista Hermosa I, Vista Hermosa II, Elba Roja, Lucitania y Tres Esquinas que hacen parte de la FVC ubicada en la vereda Travesías del municipio de Calarcá. Las familias poseen parcelaciones entre 4,8 y 5,0 ha, y son beneficiarias de un proceso de reforma agraria en el marco de la Ley 160 de 1994; desarrollan actividades productivas propias de la economía campesina con un fuerte componente organizativo y cuentan con una organización comunitaria compuesta por instancias decisorias tales como un presidente, un vicepresidente, un tesorero, un secretario y vocales. Las técnicas de recolección de la información fueron: talleres, entrevistas semiestructuradas, diálogo con miembros del hogar, lluvia de ideas, observación participante y transecto en campo. 


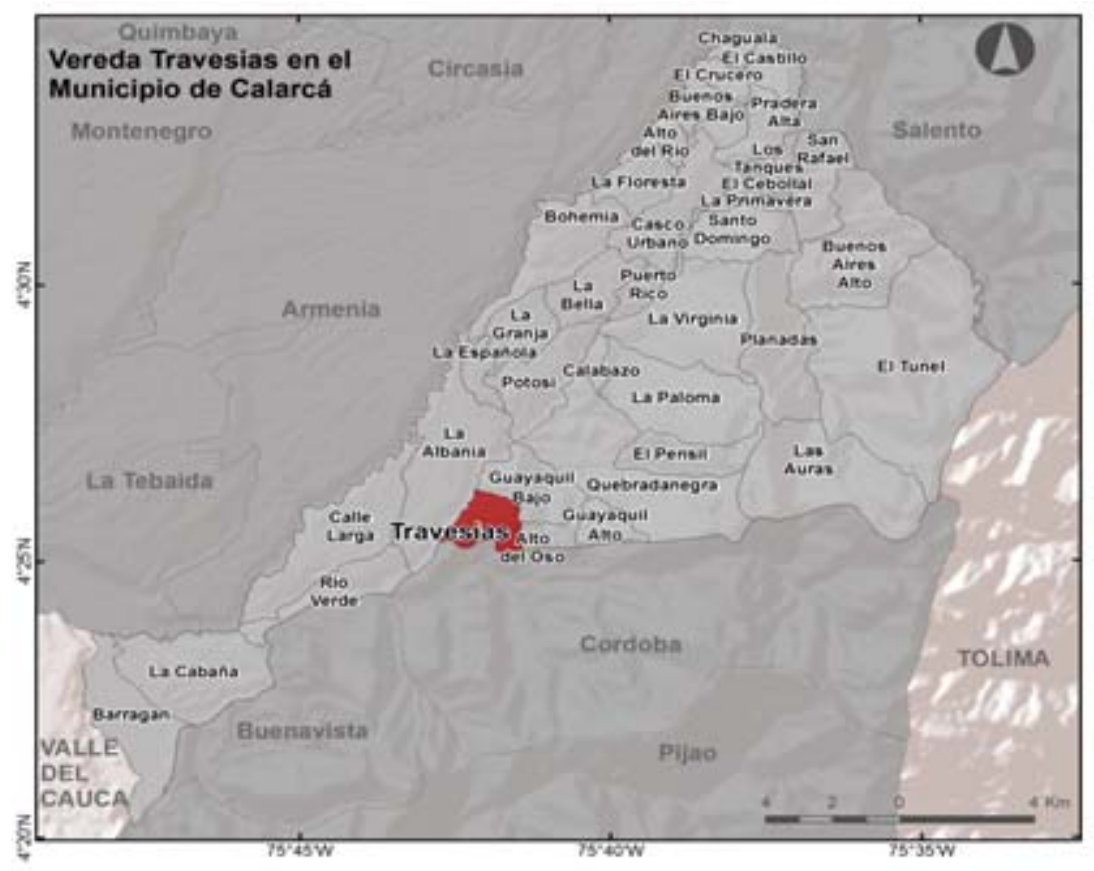

Fuente: IGAC, 2012

Figura 1. Mapa veredal - Municipio de Calarcá -Quindío

\title{
Tipo de investigación
}

Estudio de caso basado en la aplicación de la Teoría de Medios de Vida.

\begin{abstract}
Un medio de vida comprende las posibilidades o activos (que incluyen recursos tanto materiales como sociales) y actividades necesarias para ganarse la vida. Un capital es entendido como un recurso invertido para crear nuevos recursos a largo plazo, una estrategia de vida es la forma como los hogares utilizan sus activos y dotación de capitales. (DFID, 1999)
\end{abstract}

Los capitales Natural y Humano constituyen la base fundamental que las personas pueden transformar en capital social, físico, financiero y político (Flora, Flora y Fey, (2004). El Enfoque de los Medios de Vida Sostenible (EMVS) permite el análisis de los impactos que sobre el desarrollo humano y la calidad de vida, tienen los sistemas de manejo y la adopción de tecnologías, "incorporando elementos que van más allá de los indicadores económicos e índices de pobreza utilizados comúnmente. Identifica cinco categorías de activos principales o tipos de capital: Humano, Natural, Social, Físico y Financiero" (DFID, 1999).

La convertibilidad de los diferentes tipos de capitales es el mecanismo básico de las estrategias de reproducción social. Capital es un conjunto de bienes específicos que constituyen una 
fuente de poder. Entre las diferentes especies de capital se encuentran las siguientes: i) el económico, entendido como cualquier tipo de bien directamente convertible en dinero, también institucionalizado en la forma de derechos de propiedad; ii) el cultural, que puede existir en tres estados: incorporado (disposiciones, habilidades y capacidades del cuerpo y de la mente), objetivado (bienes culturales) e institucionalizado (títulos académicos); iii) el social, entendido como la capacidad de los agentes de movilizar recursos a partir de su red de relaciones sociales y iv) el simbólico, comúnmente llamado prestigio, reputación o renombre (Bourdieu, 1986, citado por Cowan y Schneider, 2008).

Los capitales estudiados fueron:

El Capital Humano: se refiere a las características de cada individuo, la inteligencia, habilidades, aptitudes, conocimientos, capacidades laborales, nivel de educación, estado de salud, que son el producto de las condiciones biológicas de cada uno y a su vez el resultado de su interacción con el entorno social

El Capital Natural: está representado por el ambiente y la oferta de recursos naturales y se constituye en la base alrededor de la cual las personas actúan y construyen sus otros capitales, este capital ofrece las posibilidades y los límites a las acciones humanas, de él hacen parte el agua, el suelo, la biodiversidad representada en las especies vegetales y animales, las características propias del paisaje como la topografía y las condiciones ambientales (DFID, 1999; Flora et al., 2004; Bermúdez, 2007).

El Capital Social: es una característica de las comunidades basada en las interacciones entre los individuos y grupos. El Capital Social se desarrolla alrededor de redes y conexiones, relaciones de confianza mutua, reciprocidad, identidad colectiva, cooperación, solidaridad y sentido de un futuro compartido (DFID, 1999; Flora et al., 2004 y Bermúdez, 2007).

El Capital Físico: está constituido por la infraestructura de carácter pública o privada y el conjunto de bienes y servicios con los que cuentan las personas para satisfacer sus necesidades básicas, realizar actividades productivas y alcanzar su desarrollo y bienestar (DFID, 1999; Flora et al., 2004; Bermúdez, 2007).

El Capital Financiero: está representado por los recursos financieros con que cuenta una familia, grupo o población, este incluye capital de inversión, créditos, ahorros, impuestos, donaciones. Es un capital importante en la definición de las estrategias de desarrollo que adopta cada hogar (DFID, 1999; Flora et al., 2004; Bermúdez, 2007).

\section{Fases del estudio}

Fase 1. Caracterización de los medios de vida de la FCV y construcción de la ficha de captura de información. Por 
medio de reuniones y visitas programadas a los nueve hogares se llevó a cabo un acercamiento con la comunidad, a través de él se crearon vínculos solidarios; esto permitió compartir y conocer de primera mano la forma de vida de los hogares, el tipo de sistemas productivos y su forma de manejo.

Se dio inicio con un diagnóstico participativo que permitió caracterizar los componentes técnicos, productivos, sociales, ambientales, culturales y políticos de cada uno de los hogares a través de la línea base que maneja la FCV.

Las técnicas para la recolección de la información en esta fase fueron: diálogo con integrantes de las familias, observación participante, fichas de captura de información, lluvia de ideas y talleres.

A partir del diálogo con los integrantes de las familias se construyeron los indicadores correspondientes a cada uno de los capitales y las fichas de captura de información.

Los capitales fueron medidos a partir de indicadores, como se presenta en la siguiente tabla.

Tabla 1. Porcentaje de ponderación para los indicadores

\begin{tabular}{|c|c|c|}
\hline Capitales & Indicador & $\begin{array}{c}\% \\
\text { Ponderación }\end{array}$ \\
\hline \multirow{3}{*}{ Capital Humano } & Nivel educativo & 30 \\
\hline & Mano de obra & 30 \\
\hline & Salud & 40 \\
\hline \multirow[b]{2}{*}{ Capital Social } & Articulación a otros grupos en la región & 60 \\
\hline & $\begin{array}{l}\text { Vinculación a políticas, programas y } \\
\text { proyectos }\end{array}$ & 40 \\
\hline \multirow{4}{*}{ Capital Natural } & Agua & 25 \\
\hline & Suelo & 25 \\
\hline & Manejo ecológico y sustentable del suelo & 25 \\
\hline & Biodiversidad & 25 \\
\hline \multirow{4}{*}{ Capital Físico } & Acceso a tierra & 50 \\
\hline & Infraestructura privada & 18 \\
\hline & Infraestructura pública & 18 \\
\hline & Máquinas y equipos & 14 \\
\hline \multirow{4}{*}{ Capital Financiero } & Efectivo & 20 \\
\hline & Ahorro & 10 \\
\hline & Ingresos & 50 \\
\hline & Crédito & 20 \\
\hline
\end{tabular}

Fuente: Ios autores.

Cada indicador se ponderó de acuerdo con su importancia y se calificó en una escala de uno a cinco; siendo cinco la mayor valoración y uno la menor. Uno representó un limitado acceso a 
los activos y cinco un acceso ideal u óptimo. El valor de cada capital se obtuvo de la sumatoria de los indicadores y su multiplicación por el valor ponderado. Los capitales se ubicaron en rangos bajos, medios o altos de acuerdo con su puntuación y para ello se compararon con los rangos de valoración que se detallan en la Tabla 2.

Tabla 2. Rango de valoración para los capitales

\begin{tabular}{|c|c|}
\hline \multicolumn{2}{|c|}{ Rango del total de los capitales } \\
\hline Bajo & $1-2,5$ \\
\hline Medio & $2,6-4,0$ \\
\hline Alto & $4,1-5$ \\
\hline \multicolumn{2}{|c|}{ Fuente: los autores. }
\end{tabular}

La medición obtenida de cada capital se expresó en una gráfica radial en forma de pentágono (gráfica AMEBA), la cual facilitó la presentación de la información acerca de los activos a la comunidad.

El pentágono de los activos en el Enfoque de Medios de Vida es una representación visual para comprender la distribución de los diferentes medios de vida que posee el hogar, donde el punto central de éste representa el acceso cero a los activos, mientras que el perímetro externo representa el acceso máximo a los mismos. (DFID, 1999)

Al totalizar la medición de los capitales en los nueve hogares se obtiene el valor general para cada uno de estos, los cuales se ubican en una escala de 1 a 25, que clasifica al hogar como bajo, medio a alto así: Bajo (si el puntaje está entre 1 y 9), Medio (si está entre 10 y 18) y Alto (si está entre 19 y 25). (Ver Tabla 3).

Tabla 3. Nivel general de cada hogar

\begin{tabular}{|l|c|}
\hline \multicolumn{2}{|c|}{ Rango del total de cada hogar } \\
\hline Bajo & $1-9$ \\
\hline Medio & $10-18$ \\
\hline Alto & $19-25$ \\
\hline
\end{tabular}

Fuente: Ios autores.

La ficha de captura de información que se aplicó recogió para cada capital: el nombre del indicador, el punto de referencia, las categorías para su valoración, su ponderación y el valor obtenido. (Tabla 4). 
Tabla 4. Fichs de capturg de información parg la medición del Capital Humano

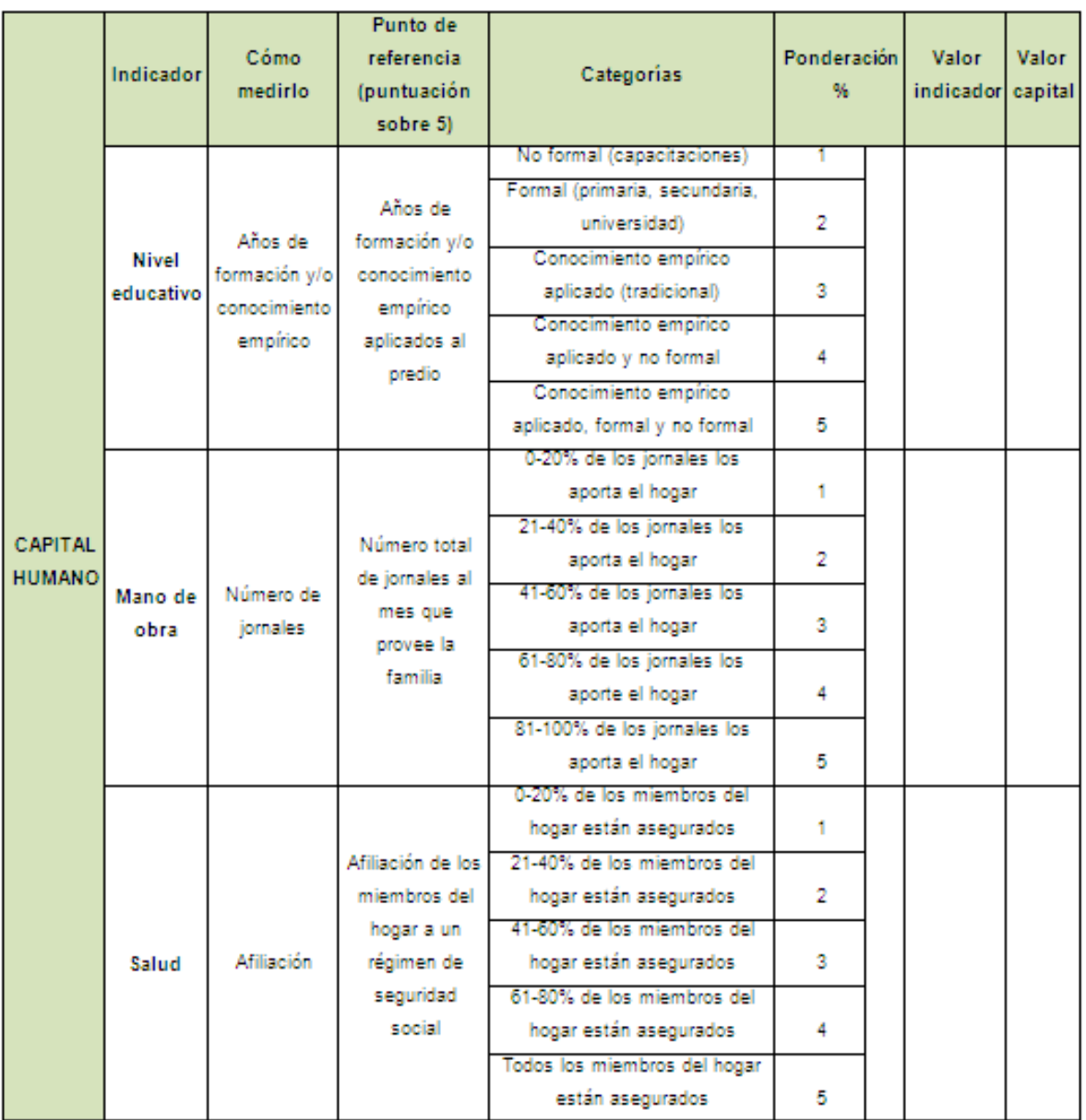

Fase 2. Recolección de la información. Para el diligenciamiento de las fichas de captura de información se aplicaron las técnicas de entrevista semiestructurada y transecto en campo en cada uno de los hogares.

Las entrevistas se realizaron con todos los miembros del hogar, lo cual permitió la captura de información, el abordaje de cada capital y de sus correspondientes indicadores, facilitando un espacio de reflexión familiar. De esta manera se obtuvo la evaluación para cada uno de los indicadores y el capital correspondiente.

\section{Fase 3: Análisis y resultados}

La información que se obtuvo del estudio para cada uno de los nueve hogares fue la siguiente: caracterización de los hogares, descripción de los capitales y análisis general de los mismos para cada hogar e identificación de las estrategias de vida. 


\section{RESULTADOS}

\section{Caracterización de los hogares de la FCV}

Las familias de la FCV poseen parcelaciones entre 4,8 y 5,0 ha, $y$ son beneficiarias de un proceso de reforma agraria en el marco de la Ley 160 de 1994; entre los miembros de la FCV se han realizado ventas y permutas de lotes, llama la atención cómo una gran parte de estos negocios no se realizan con documentos sino por medio de lo que ellos llaman "negocios de buena fe o de palabra"; sin embargo, después de un tiempo, algunos inician trámites de escrituración. Los lotes cedidos a familiares o negociados con vecinos no son medidos, pero los acuerdos entre las partes son respetados y gracias a ello se mantienen buenas relaciones de convivencia.

De los 3.237 predios rurales que reporta el municipio de Calarcá, el $75,22 \%$ tiene un área menor e igual a 5 hectáreas, rango donde se ubican los predios de la FCV (Gobernación del Quindío, 2009).

Por el tamaño de los predios y de acuerdo a la clasificación que hace la Federación Nacional de Cafeteros de Colombia, estos agricultores son considerados como pequeños propietarios, lo que los ubica dentro del $94,7 \%$ de los caficultores de Colombia que tienen un tamaño de predio igual o menor a 5 hectáreas (Federacafé, 1997).

Las fincas tienen como cultivos principales la asociación entre café y plátano, solo un predio sembró el cultivo de lulo pero ya decidieron erradicarlo y volver a sembrar café, todos registran otros cultivos para consumo familiar como: maíz, frijol, yuca, frutales, entre otros. Los hogares son propietarios de los predios lo que se constituye en una fortaleza de esta comunidad al tener como principal indicador dentro del Capital Físico el acceso a la tierra.

La composición familiar de los hogares de la FCV es la siguiente: de los nueve, el 55,55\% (5 hogares) está conformado por 4 miembros, el 22,22\% (2 hogares) por tres miembros, un hogar $11,11 \%$ por 2 miembros y un hogar $11,11 \%$ por 11 miembros para el $100 \%$ y un total de 39 personas en esta comunidad. El promedio de miembros para los nueve hogares es de cuatro integrantes, igual al promedio nacional que es de 4,3 personas en los hogares cafeteros (Fonseca, 2003). Solo un hogar tiene 11 integrantes.

El $64,1 \%$ de los miembros de la comunidad son hombres y el $34,9 \%$ son mujeres, solo en uno de los nueve hogares la cabeza de familia es una mujer, en los demás hogares figuran hombres; el $30,77 \%$ son personas menores de 20 años y su principal actividad es la educación, el $12,82 \%$ son personas mayores de 60 años; 21 personas (el 56,41\%) están entre los 20 y los 60 años, considerado este como el rango de vida laboral activa. Los adultos mayores, mujeres, niños y jóvenes colaboran en 
actividades agropecuarias puntuales ya que no dedican el $100 \%$ de su tiempo a las mismas.

La producción agrícola está basada en el autoconsumo y en la venta de productos para el mercado local en los siguientes renglones: cría de peces, lulo, café tradicional, leche, plátano, cacao, frijol, caña, cítricos, yacón, arroz secano, aguacate, yuca, maíz criollo, banano común, banano, papaya, limón, ají dulce, sábila, hortalizas y aromáticas. El café es comercializado en la Cooperativa de Caficultores de Calarcá y el plátano se vende a quien pague mejor precio. De las nueve fincas, solo una diversifica y recupera semillas tradicionales.

Esta diversidad es típica de la producción campesina ya que de acuerdo con Berdegue y Larrain (1988):

[...] la producción campesina funciona con base en la organización de diferentes rubros interactivos en el marco de un predio, algunos de ellos orientados al intercambio externo, y otros, al autoconsumo. Por tanto en la producción campesina, la toma de decisiones está supeditada a la obtención de un producto predial, y no a un rubro en particular. (Mora-Delgado, 2008)

Las labores de manejo que reportan las familias son: desyerba, plateo, abono y resiembra; el $100 \%$ de la mano de obra es realizada por los miembros del hogar, generalmente los hombres. En ninguno de los hogares se lleva registro de labores, solo en uno se tienen en cuenta los gastos.

El 90\% de los hombres de los hogares trabaja por jornales en fincas vecinas, lo que combinan con las labores del predio. Las mujeres se desenvuelven como amas de casa y se dedican a las actividades del hogar, también aportan a las labores de la finca. Es evidente la planificación de las labores, las realizan como lo hace cualquier agricultor que establece un orden en las mismas, según la época del año y el clima, tienen poco conocimiento técnico, su trabajo se hace con base en los conocimientos empíricos como por ejemplo utilizar agroquímicos indiscriminadamente sin ninguna valoración previa, no utilizan análisis químico de los suelos para realizar los abonamientos, entre otras acciones no planificadas.

La producción no es tecnificada en ninguno de los renglones, es básicamente tradicional y se basa en el conocimiento empírico que los miembros de los hogares han aprendido de sus padres y familiares. En todas las fincas se usan agrotóxicos y utilizan fertilizantes químicos; algunas están iniciando un proceso de reconversión hacia agricultura limpia.

Los nueve hogares reportan como la época de mayor dificultad económica, los meses entre junio y agosto donde no hay cosecha de café; también en las épocas invernales donde se presentan pérdidas en las floraciones del café lo que conlleva a 
pérdidas económicas considerables, tal como ocurrió a nivel del país en los años 2009 a 2012 cuando los niveles de producción bajaron alrededor de un $36 \%$ debido principalmente a la ola invernal.

En estos meses las familias viven de los ingresos percibidos por otros renglones productivos como venta de especies menores, venta de plátano, frutales y venta de mano de obra. Aunque los ingresos son muy bajos, les permite mantener un flujo mínimo para la compra de alimentos y poder cumplir con los créditos bancarios que la gran mayoría de ellos posee.

\section{Descripción y análisis general de los capitales}

A partir de la obtención de los resultados de la medición de los cinco capitales con base en sus indicadores, se establecieron aquellos que presentan mayores valoraciones y que por tanto constituyen activos y/o medios de vida, y aquellos que constituyen restricciones al logro de las estrategias de vida. Los capitales de mayor valoración fueron el Humano con una media de 4,16 y el Físico con una media de 4,04; los capitales con menor valoración fueron el Social con una media de 3,09 y el Financiero con una media de 3,29. El Capital Natural se ubica en un rango medio con respecto a los demás de 3,56 (Tabla 5).

Tabla 5. Valor de los capitales con sus correspondientes indicadores

\begin{tabular}{|c|c|c|c|c|}
\hline Capitales & Indicador & $\begin{array}{c}\text { Valor } \\
\text { indicador }\end{array}$ & Media & $\begin{array}{l}\text { Desviación } \\
\text { estándar }\end{array}$ \\
\hline \multirow{3}{*}{ Capital Humano } & Niveleducativo & 1,1 & \multirow{3}{*}{4,16} & \multirow{3}{*}{0,44} \\
\hline & Mano de obra & 1,17 & & \\
\hline & Salud & 1,9 & & \\
\hline \multirow[b]{2}{*}{ Capital Social } & Articulacion a otros grupos en la region & 2,3 & \multirow[b]{2}{*}{3,09} & \multirow[b]{2}{*}{0,67} \\
\hline & $\begin{array}{l}\text { Vinculaciona politicas, programas y } \\
\text { proyectos }\end{array}$ & 0,93 & & \\
\hline \multirow{4}{*}{ Capital Natural } & Agua & 0,64 & \multirow{4}{*}{3,56} & \multirow{4}{*}{0,37} \\
\hline & Suelo & 1,08 & & \\
\hline & $\begin{array}{l}\text { Manejo ecologico y sustentable del } \\
\text { suelo }\end{array}$ & 0,97 & & \\
\hline & Biodiversidad & 0,92 & & \\
\hline \multirow{4}{*}{ Capital Físico } & Acceso a tierra & 2,44 & \multirow{4}{*}{4,04} & \multirow{4}{*}{0,51} \\
\hline & Tnfraestructura privada & 0,52 & & \\
\hline & Tnfraestructura publica & 0,52 & & \\
\hline & Maquinas y equipos & 0,51 & & \\
\hline \multirow{4}{*}{$\begin{array}{c}\text { Capital } \\
\text { Financiero }\end{array}$} & Efectivo & 0,31 & \multirow{4}{*}{3,29} & \multirow{4}{*}{0,34} \\
\hline & Ahorro & 0,1 & & \\
\hline & Tngresos & 1,94 & & \\
\hline & Credito & 0,93 & & \\
\hline
\end{tabular}

Fuente: los sutores.

\section{Capital Humano}


Este capital se evaluó por medio de los indicadores: Nivel Educativo, Mano de Obra y Salud, cuyas valoraciones se presentan en la Tabla 6. El Capital Humano en los nueve hogares presentó una valoración alta en relación con los otros capitales, 6 de los 9 hogares muestran puntuaciones entre 4,1 y 5 y los otros tres, puntuaciones entre 3,4 y 3,8 ubicándose en un rango medio.

Tabla 6. Capital Humano para todos los hogares

\begin{tabular}{|c|c|c|c|c|}
\hline \multirow{11}{*}{$\begin{array}{l}\text { Capital } \\
\text { Humano }\end{array}$} & \multirow{2}{*}{ Nombre de la finca } & \multicolumn{3}{|c|}{ Valor del rango del capital } \\
\hline & & Bajo & Medio & Alto \\
\hline & El Triángulo & & 3,8 & \\
\hline & ElMilagro & & & 4,1 \\
\hline & La Favorita & & & 4,1 \\
\hline & ElOso & & & 4,7 \\
\hline & Vista Hermosal & & & 4,4 \\
\hline & VistaHermosall & & 3,4 & \\
\hline & Elba Roja & & & 4,7 \\
\hline & Lucitania & & 3,8 & \\
\hline & Tres Esquinas & & & 4,4 \\
\hline
\end{tabular}

Fuente: los gutores.

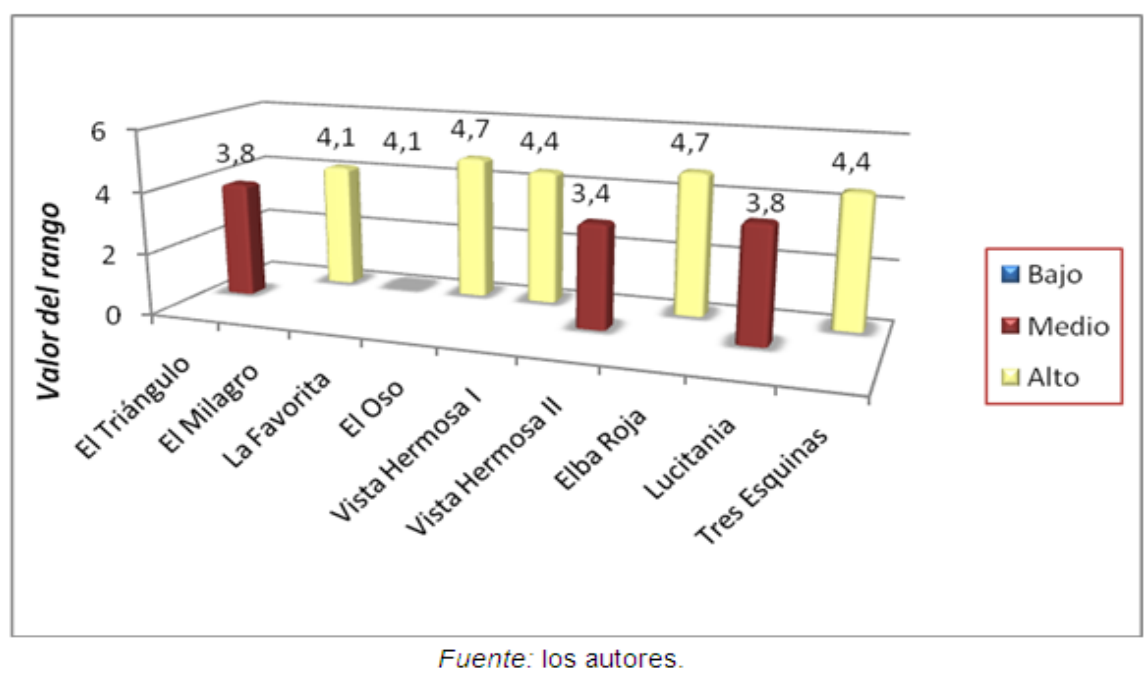

Figura 2. Distribución del Capital Humano para todos los hogares.

En el Nivel Educativo se determinaron los años de formación, el conocimiento empírico aplicado al predio y la educación no formal relacionada con cursos y/o capacitaciones recibidas por los miembros del hogar y empleados en las labores de la finca. Este indicador le dio un valor muy importante a los conocimientos empíricos y tradicionales propios de los agricultores de economía campesina. El indicador Mano de Obra determinó el número total de jornales al mes que proveen los miembros de la familia, y con 
el indicador de Salud se buscó conocer el nivel de afiliación de los miembros del hogar a un régimen de seguridad social.

El análisis del Capital Humano en los nueve hogares mostró que las personas en edades mayores de 40 años presentaron un nivel de escolaridad bajo, porque en su mayoría reportan estudios formales menores o iguales a 3 años. El 66,6\% de los hogares reporta el indicador de educación como el de menor valor. Sin embargo, se observó que a pesar de la falta de educación formal poseen una gran experiencia y conocimientos empíricos relacionados con el manejo de la finca que han sido heredados de sus padres y complementados con la experiencia de muchos años de dedicación a las labores agrícolas.

Todos los niños pertenecientes a estos hogares asisten a las escuelas cercanas a sus predios, algunos de ellos reciben subsidio de transporte si estudian en las escuelas de las veredas vecinas. Se presenta el caso de un adolecente que trabaja en semana colaborando con las labores productivas en el predio y asiste al colegio los fines de semana para terminar los grados 10 y 11 en validación. El hacer parte de una comunidad organizada les ha permitido tener acceso a capacitaciones, cursos y talleres que desarrollan las instituciones que hacen presencia en la vereda; sin embargo, esto no es considerado una ayuda suficiente por parte de los integrantes de la comunidad.

El Capital Humano en estos hogares se caracterizó por el aporte en mano de obra familiar; el $100 \%$ de los miembros de las familias contribuyen con su mano de obra a las labores de la finca, estas se distribuyen de acuerdo a las edades y tipo de labores. La disponibilidad de mano de obra familiar es un medio de vida de suma importancia en los logros relacionados con los medios de vida, pues fortalece y aporta a la economía campesina. En este análisis se evidenció que hay hogares que cuentan con pocos integrantes; sin embargo, asumen de manera colectiva las labores del predio, lo cual disminuye la contratación de terceros. Algunas familias contratan uno o dos trabajadores, sobre todo en época de cosecha cafetera. Las mujeres, además de encargarse de las labores del hogar, ayudan en el proceso productivo y el manejo de especies menores; en ninguno de los casos se evidenció explotación de mano de obra infantil.

Los integrantes de los hogares cuentan con un cubrimiento del $100 \%$ en seguridad social, el acceso a este activo es importante para el mejoramiento de las condiciones de vida de las familias y eleva ampliamente los logros en materia de medios de vida.

\section{Capital Social}

Es el capital que más baja valoración presenta entre los cinco evaluados con una media de 3,06.

Siete de los nueve hogares presentan una valoración media, lo que significa que la vinculación y participación de las familias a grupos y redes de la vereda está entre el 21 y el $40 \%$, esto representa un activo importante en términos de la capacidad de 
planificación y acción colectiva que han ido configurando con otras organizaciones e instituciones, lo que les da mayor capacidad de negociación y acceso a proyectos y recursos del Estado y otras instituciones (Tabla 7).

Tabla 7. Capital Social para todos los hogares

\begin{tabular}{|c|c|c|c|c|}
\hline & \multirow{2}{*}{ Nombre de la finca } & \multicolumn{3}{|c|}{ Valor del rango del capital } \\
\hline \multirow{10}{*}{$\begin{array}{l}\text { Capital } \\
\text { Social }\end{array}$} & & Bajo & Medio & Alto \\
\hline & El Triángulo & & 2,8 & \\
\hline & El Milagro & & 2,6 & \\
\hline & La Favorita & & 3,6 & \\
\hline & ElOso & 2,2 & & \\
\hline & Vista Hermosa I & & & 4,2 \\
\hline & Vista Hermosa II & & 3,6 & \\
\hline & Elba Roja & & 2,6 & \\
\hline & Lucitania & & 2,6 & \\
\hline & Tres Esquinas & & 3,6 & \\
\hline
\end{tabular}

Fuente: Ios autores.

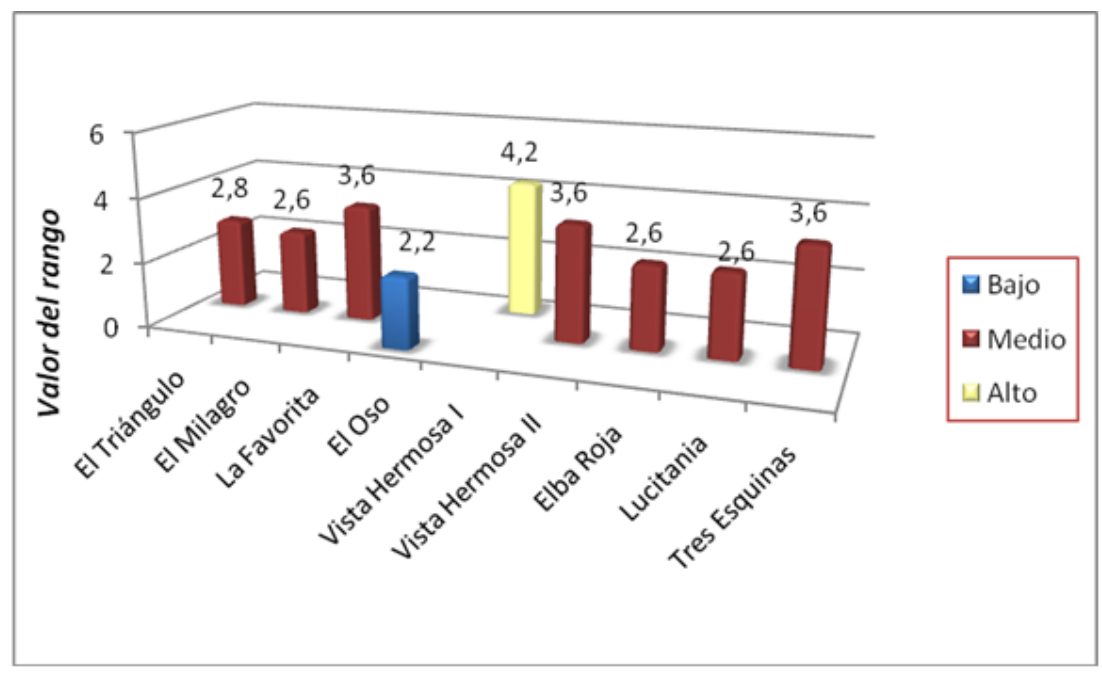

Fuente: Ios autores

Figura 3. Capital Social para todos los hogares.

El Capital Social se midió a partir de dos indicadores: Articulación y participación de los integrantes del hogar a grupos de trabajo, redes y/o asociaciones existentes en la región tales como: mingas, Juntas de Acción Comunal, trueques, encuentros comunales, JOVEARTE y ASOFAMIAGRO y la vinculación a 
políticas, programas y proyectos realizados en la vereda de los cuales se pueden beneficiar los hogares.

Con base en el indicador Articulación y participación de los integrantes del hogar a grupos de trabajo, redes y/o asociaciones existentes en la región, se encontró una asidua participación de los miembros de los hogares a grupos y redes de la región y la vereda tales como: JOVEARTE, grupo de mujeres campesinas, atención a visitas de estudiantes universitarios y asistencia a ferias agropecuarias; esto representa beneficios a nivel social y permite espacios de inclusión y reconocimiento. La FCV ha asumido el reto de generar procesos de desarrollo endógeno y ello se ve reflejado en los programas, proyectos y actividades que gestionan colectivamente con este propósito. Aparte de la FCV, los hogares se articulan a otros espacios sociales que generen beneficios para su territorio, tales como: cursos del SENA, asistencia técnica por parte de la UMATA y vinculación al programa de Incentivo a la Capitalización Rural para la renovación de los cultivos de café.

El activo social con el que cuenta esta comunidad crea mayor acceso o vinculación a proyectos y programas que se realizan en el territorio, pero la dinámica de organización social que manejan, se encuentra ligada a su realidad temporal, esto significa que no todas las personas tienen los mismos intereses y horarios disponibles para asistir y participar de las reuniones, así que quienes pueden asistir, trasmiten la información a sus vecinos aprovechando encuentros casuales como son los caminos que transitan o las visitas a las fincas, también en encuentros que realizan en zonas recreativas o en el municipio; esta situación no refleja realmente una participación funcional o por toma de decisiones; se evidencia un propósito de la Fundación que es mantener una red de información que les permita socializar las problemáticas y las acciones a seguir; en este contexto se realizan mingas y trueques que tienen por objetivo unir esfuerzos para las labores agrícolas y/o una actividad que requiera la comunidad; sin embargo, esto no es visto por los miembros de los hogares como una estrategia de vida importante y por el contrario se presenta con la valoración más baja de todos los capitales.

Para el $44,44 \%$ de los hogares este es el capital de menor valoración y en el $100 \%$ de ellos el indicador de articulación a otros grupos de la región está por encima de la vinculación a políticas, programas y proyectos. La anterior afirmación tiene que ver más con el proceso organizativo local que presenta la comunidad, lo que le permite un mayor acceso a las informaciones y posibilidad de desarrollar procesos de articulación con otros grupos.

Llama la atención que una comunidad que fue sujeta de otorgamiento de predios a través de la reforma agraria y que tienen acceso a las ayudas, subsidios y estímulos que otorga Federacafé a sus agremiados, no se vincule a los mismos o le den poca valoración a estos indicadores. En palabras de la misma comunidad "son muchos los programas e instituciones 
que hacen presencia en la vereda, pero poco el acceso que tienen a ellos, por los requisitos que exigen".

\section{Capital Natural}

Ocho de los nueve hogares de la FCV presentan una valoración media entre 3,0 y 3,75 para este indicador (Tabla 8).

Tabla 8. Capital Natural para todos los hogares

\begin{tabular}{|c|c|c|c|c|}
\hline \multirow{11}{*}{$\begin{array}{l}\text { Capital } \\
\text { Natural }\end{array}$} & \multirow[t]{2}{*}{ Nombre de la finca } & \multicolumn{3}{|c|}{$\begin{array}{c}\text { Valor del rango del } \\
\text { capital }\end{array}$} \\
\hline & & Bajo & Medio & Alto \\
\hline & El Triángulo & & 3,3 & \\
\hline & El Milagro & & 3,8 & \\
\hline & LaFavorita & & 3,5 & \\
\hline & ElOso & & 3,8 & \\
\hline & Vista Hermosa I & & 3,8 & \\
\hline & Vista Hermosa II & & 3,3 & \\
\hline & Elba Roja & & 3,0 & \\
\hline & Lucitania & & & 4,3 \\
\hline & Tres Esquinas & & 3,5 & \\
\hline
\end{tabular}

Fuente: los autores.

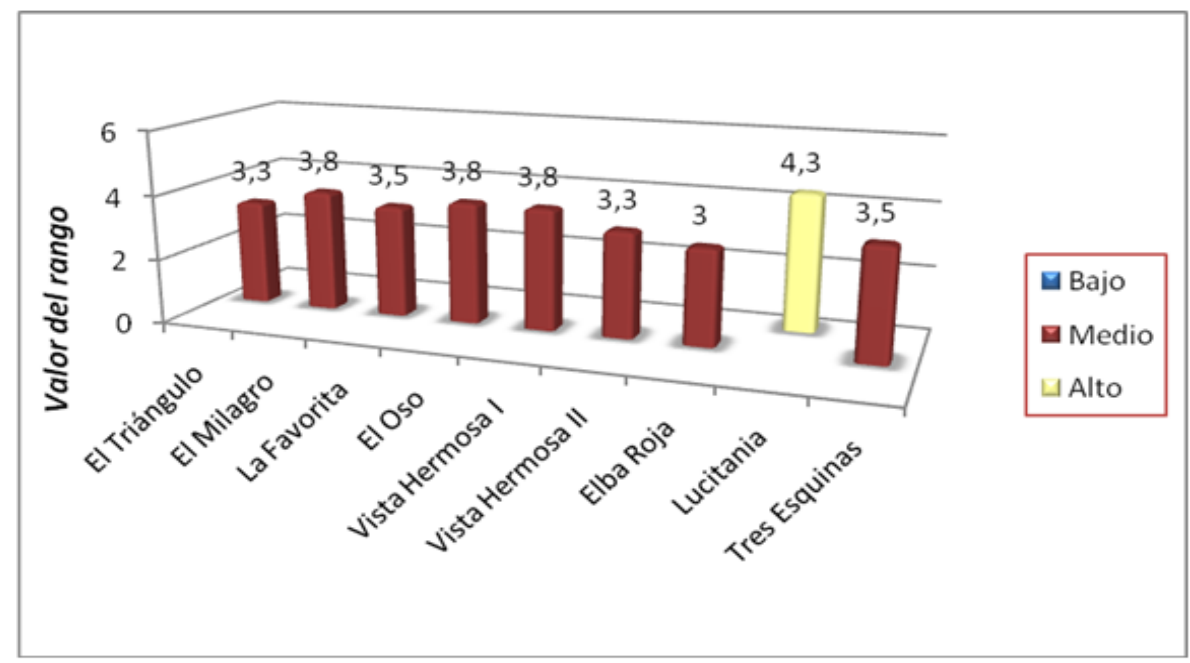

Fuente: Ios autores.

Figura 4. Distribución del Capital Natural para todos los hogares. 
El Capital Natural se midió con base en cuatro indicadores: Agua, cuya valoración se obtuvo teniendo en cuenta el acceso que el hogar tiene a nacimientos y su protección. El segundo indicador fue el Suelo, medido por la cantidad de área en uso productivo que le da cada hogar a su predio; el tercer indicador fue Manejo Ecológico y Sustentable del Suelo de acuerdo con la aplicación de prácticas para la conservación y el uso ecológico y sustentable del mismo (sombríos permanentes, manejo de trinchos, coberturas muertas, manejo de terrazas, selección de arvenses nobles, labranza mínima, curvas a nivel, barreras vivas, manejo de abonos verdes y aplicación de materia orgánica).

El cuarto indicador fue Biodiversidad por medio del cual se identificaron las prácticas agrícolas y pecuarias que favorecen la biodiversidad de las fincas a saber: policultivos, asociación de cultivos, MIPE ${ }^{5}$, áreas protegidas, conservación y recuperación de semillas nativas, insumos químicos permitidos en producción limpia, manejo apropiado de residuos sólidos y líquidos, pozos sépticos, arreglos silvopastoriles y agrosilvopastoriles.

En el Capital Natural el indicador relacionado con el suelo es el de mayor calificación, para $7(77,77 \%)$ de los nueve hogares este es el más significativo, lo que refleja la importancia que para esta comunidad tiene el acceso a la tierra y poderla cultivar, en cambio el indicador más bajo es el agua, como lo evidencian el $44,4 \%$ de los hogares.

El limitado acceso al agua de algunos hogares y la utilización de productos químicos en las labores agrícolas -sin ningún tipo de prevención-, son algunos de los aspectos que limitan o restringen el acceso a esta estrategia de vida. La conciencia que tiene la comunidad acerca de la necesidad de conservar el suelo y la diversificación de actividades agrícolas y pecuarias se presenta como una fortaleza, sin embargo, se hace necesario llevar a cabo la planificación de las labores agrícolas en las que se pongan en práctica conocimientos agroecológicos relacionados con el manejo del suelo, la fertilización, la agro y biodiversidad. Es muy evidente el uso e inadecuado manejo que los agricultores hacen de los productos de síntesis química.

El acceso al agua es un componente de gran importancia en cualquier proceso productivo, este se presenta como una debilidad para algunos de los hogares ya que cuatro de los nueve no poseen nacimientos y tampoco tienen acceso a alguno, sin embargo, se surten del acueducto veredal construido por el Comité de Cafeteros del Quindío; otros cuatro hogares cuentan con nacimiento dentro del predio y realizan prácticas de conservación; un hogar no cuenta con nacimiento pero tiene acceso a uno, el cual también protege dentro del espacio que corresponde al predio.

En cuanto al uso del suelo, los predios se caracterizan por tener la mayor área de producción en café, en casi todos los hogares el área de producción no es exclusiva solo para este producto, la asociación con plátano o banano representa una opción de 
ingresos, sobre todo en épocas del año donde no hay cosecha de café o hay temporada invernal.

Adicional a estos cultivos se encontró en los nueve hogares una diversidad de frutales tales como: aguacate, cacao y cítricos; en menor proporción o por épocas del año se cultiva maíz, yuca y fríjol que no solo permiten ingresos en efectivo sino también autoconsumo. Solo en la finca El Oso se presentó abundante diversificación representada por café, plátano, banano, aguacate, cacao, cítricos, arroz, yuca, caña y hortalizas; en este aspecto es importante referenciar que se trata de predios de solo 5 ha.

Aunque la producción agrícola se identificó como la actividad predominante en estos hogares, es de resaltar que cuatro de ellos realizan combinación de actividades agrícolas y pecuarias; la producción animal se lleva a cabo para la vinculación al mercado y para el consumo familiar, es otra forma de solventar las necesidades económicas y alimentarias. Se encontró que en todos estos hogares se manejan franjas de conservación en el uso del suelo.

Las prácticas de producción de los nueve hogares de la FCV son tradicionales y van direccionadas a la conservación del medio ambiente y al consumo mínimo de insumos externos, sin embargo, se evidenció poco conocimiento acerca del control cultural de plagas y enfermedades. Ante ataques fuertes, la gran mayoría de los agricultores hace uso de insumos agrícolas de altas categorías toxicológicas, algunos de ellos sin las condiciones necesarias de prevención para su manejo, componente que pone en riesgo su salud y la de la familia.

Aunque el territorio en el que viven los hogares pertenecientes a la FCV está muy influenciado por los monocultivos de café y plátano, algunos de estos se resisten a perder su diversidad y se proponen mantener más de una actividad agrícola y pecuaria en sus fincas para conservar la vinculación con el mercado local y aportar a la dieta alimentaria familiar. Los líderes de la organización están buscando crear conciencia entre las generaciones jóvenes y entre los vecinos de la vereda acerca de la importancia de la conservación de semillas, del agua, de los suelos y la diversificación para beneficio propio y de las generaciones futuras.

\section{Capital Físico}

En la valoración del Capital Físico se tuvieron en cuenta cuatro indicadores: el primero fue el Acceso a la tierra, medido por el tipo de tenencia que el hogar tiene sobre la propiedad donde habita; el segundo indicador midió la Infraestructura privada, el cual valoró la cantidad y la calidad de la infraestructura doméstica y productiva disponible para el hogar, y el tercer indicador se basó en la Infraestructura pública de acuerdo con el acceso a servicios públicos (agua potable, energía eléctrica, alcantarillado) (Tabla 9). 
Tabla 9. Capital Físico para todos los hogares

\begin{tabular}{|c|l|c|c|c|}
\hline \multirow{4}{*}{\begin{tabular}{c} 
finca \\
\multirow{4}{*}{$\begin{array}{c}\text { Capital } \\
\text { Físico }\end{array}$}
\end{tabular}} & \multicolumn{3}{c|}{$\begin{array}{c}\text { Valor del rango del } \\
\text { capital }\end{array}$} \\
\cline { 2 - 5 } & El Triángulo & & 3,2 & \\
\cline { 2 - 5 } & El Milagro & & & 4,1 \\
\cline { 2 - 5 } & La Favorita & & & 4,6 \\
\cline { 2 - 5 } & El Oso & & & 4,5 \\
\cline { 2 - 5 } & Vista Hermosal I & & 3,5 & \\
\cline { 2 - 5 } & Vista Hermosa II & & 3,5 & \\
\cline { 2 - 5 } & Elba Roja & & & 4,5 \\
\cline { 2 - 5 } & Lucitania & & 3,9 & \\
\cline { 2 - 5 } & Tres Esquinas & & & 4,5 \\
\hline
\end{tabular}

Fuente: Ios autores.

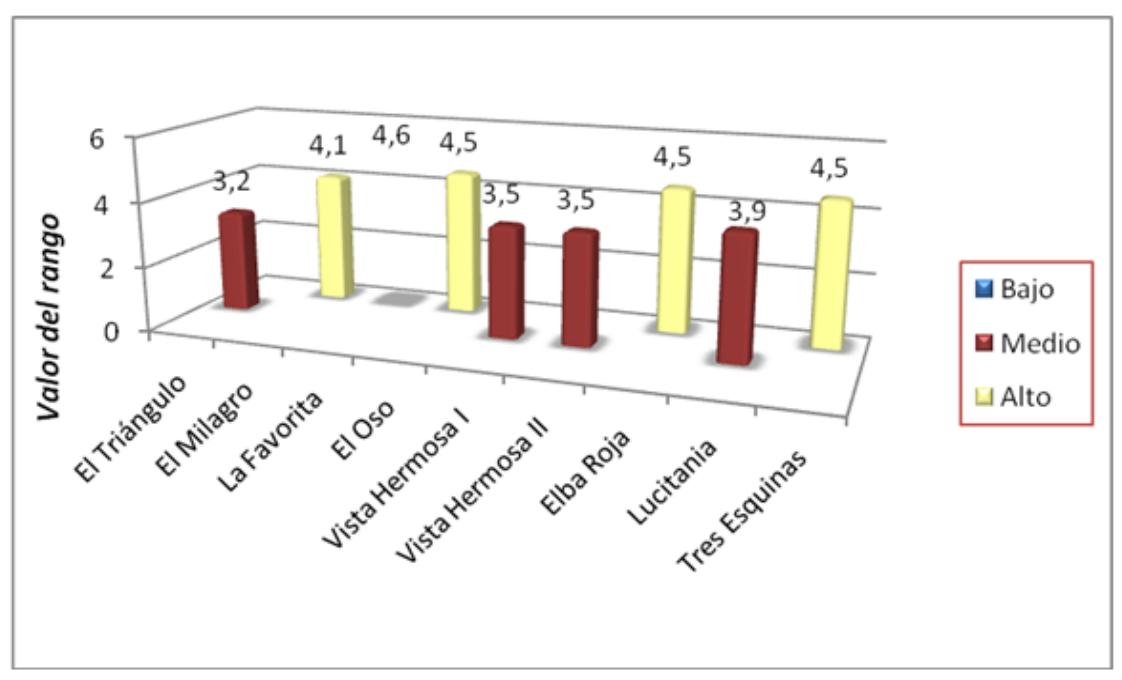

Fuente: Ios autores

Figura 5. Capital Físico para todos los hogares.

El Capital Físico, al igual que el Capital Humano, presenta un comportamiento favorecido por la ubicación de los hogares, cinco de ellos en un rango alto y los otros cuatro en un rango medio, con puntuaciones que varían entre 3,2 y 4,6 (Figura 5).

En cuanto a la tenencia de la tierra, los hogares de la FCV cuentan con áreas de minifundio que están entre 4,8 y 5 ha, la gran mayoría de ellas tiene franja de conservación y excepto por 
un caso donde el hogar es poseedor de buena fe, los demás son propietarios.

Según la Resolución 041 de septiembre 24 de 1996 del Instituto Colombiano de la Reforma Agraria, desde la Oficina de Formalización y Legislación Agraria se estableció para los municipios de Calarcá, Génova, Pijao, Buenavista, Salento y Córdoba una Unidad Agrícola Familiar (UAF) de entre 6 y 12 ha, de acuerdo con la potencialidad productiva de los predios de estos municipios, por encima del promedio del área que tienen los habitantes de FCV (Instituto Colombiano de la Reforma Agraria - Ministerio de Agricultura, 1996), esto indica que los predios de la FCV no cuentan con un área suficiente que garantice a las familias ingresos y/o condiciones de seguridad alimentaria, lo cual reduce de manera sustancial las posibilidades de medios de vida de acuerdo con los indicadores de los capitales que está midiendo el estudio, lo que obliga a las familias a desplegar otras alternativas para generar estrategias de vida.

En cuanto a la infraestructura privada, se evidenció que los nueve hogares cuentan con las condiciones básicas necesarias para su subsistencia. Con el beneficio recibido del Programa del Fondo para la Reconstrucción y Desarrollo Social del Eje Cafetero (FOREC), ejecutado después del terremoto ocurrido en el año 1999, estos hogares tuvieron la oportunidad de hacer inversiones en infraestructura productiva, mejoramiento y/o adecuación de la vivienda familiar a través de este proyecto, aun así algunos de ellos no lograron terminar las obras o requieren mantenimiento. Los hogares mostraron necesidades en cuanto a mejoras en los beneficiaderos para procesar el café, se presentó el caso de un hogar que requiere de la construcción total de su infraestructura doméstica.

Las condiciones básicas necesarias para la subsistencia se refieren a que en tres de los hogares las viviendas son habitables, aunque tienen pisos en tierra y las paredes son de esterilla. La totalidad de las viviendas de la comunidad cuenta con servicio sanitario, agua y luz eléctrica, además de que la infraestructura productiva se encuentra en condiciones aceptables.

La infraestructura pública que evalúa el acceso que tiene el hogar a los servicios públicos indica que son predios que cuentan con vías de acceso deficientes, las cuales se han logrado recuperar gracias a las mingas que realiza la comunidad y a las gestiones para lograr el apoyo de algunas instituciones gubernamentales. Aunque para la mayoría de estos hogares, la cercanía con el corregimiento de Barcelona les reduciría tiempo y costos de transporte, se evidenció que el desplazamiento debe hacerse al municipio de Calarcá porque se requiere de un puente que permita la movilización de autos entre Barcelona y Travesías, solitud realizada hace unos años por la comunidad a la administración municipal y que todavía no ha sido tenida en cuenta. 
En relación con los servicios públicos básicos como agua potable y energía eléctrica, se encontró un predio que utiliza el agua del nacimiento para las labores, tanto productivas como domésticas, prescindiendo del servicio de acueducto veredal, otro caso fue el de un hogar que comparte los servicios con el predio vecino, los demás hogares cuentan con todos los servicios públicos.

Uno de los indicadores que midió este capital son las maquinarias, equipos y/o herramientas que poseen los hogares para realizar sus actividades productivas, en este sentido se encontró que en su totalidad no utilizan maquinaria y manejan solo las herramientas necesarias, con los cuidados que se requiere para su mantenimiento.

Cinco de los nueve hogares presentan un rango alto para este capital, los hogares tienen como fortaleza el ser propietarios de sus predios y tener viviendas adecuadas con todos los servicios públicos. Algunas debilidades que presentan es carecer de infraestructura productiva acorde con sus necesidades, e inadecuadas vías de acceso al no contar con una carretera al corregimiento más cercano.

La mayor fortaleza en este capital se encuentra en la tenencia de la tierra, el hecho de que todos sean propietarios les ha permitido obtener beneficios como fue el aporte recibido para la reconstrucción de la infraestructura después del terremoto de 1999 y el acceso a créditos bancarios; esta condición constituye una estrategia de vida para los hogares de la FCV.

El estado de la infraestructura productiva de los hogares depende considerablemente de su acceso al Capital Financiero y a los ingresos que perciben, ya que podrían destinar parte de estos al mantenimiento y/o construcción de infraestructura. Sin embargo, la gran mayoría de ellos manifiesta que los ingresos percibidos por las labores agrícolas no son suficientes para la cancelación de las cuotas de los créditos bancarios y menos para invertir en el mantenimiento de la infraestructura productiva, viéndose en la necesidad de complementar sus fuentes de ingreso con otras actividades, entre ellas, el turismo rural. Algunas familias han migrado por factores de violencia, amenazas y/o asesinatos dentro del conflicto armado que se vive en el país y que no es ajeno a esta zona.

\section{Capital Financiero}

El Capital Financiero presenta un comportamiento de rango medio para todos los hogares con puntuaciones que varían entre 2,8 y 3,8 . Para los pequeños productores que manejan economía campesina este es un capital al que tienen limitaciones de acceso principalmente porque el portafolio de actividades que desarrollan genera ingresos para dar continuidad al proceso productivo y suplir las necesidades básicas de los hogares, pero la falta de efectivo para realizar nuevas inversiones determina, en cierta medida, el acceso que estos hogares tengan a otros activos, factor que se ve reflejado en las valoraciones de cada capital. 
Para determinar el Capital Financiero se tuvieron en cuenta cuatro indicadores: Efectivo, que permitió medir el porcentaje de dinero disponible con que cuentan los hogares; Ahorro, medido en el porcentaje de los ingresos que la familia guarda como reserva para destinar a inversiones, pagos futuros 0 ser utilizados en momentos de crisis; Ingresos, medido por el tipo de fuente que utiliza el hogar para generar diversidad de ingresos y Crédito que midió el acceso que el hogar tiene a préstamos para cubrir sus necesidades productivas y/o familiares.

La siguiente información presenta la valoración y el rango obtenido por cada hogar para el Capital Financiero, todos los hogares de la FCV se ubican en un rango medio para el capital Financiero (Tabla 10, Figura 6).

Tabla 10. Medición del Capital Financiero para todos los hogares

\begin{tabular}{|c|l|c|c|c|}
\hline \multirow{4}{*}{$\begin{array}{c}\text { finca } \\
\text { fombre de la }\end{array}$} & \multicolumn{3}{|c|}{$\begin{array}{c}\text { Valor del rango del } \\
\text { capital }\end{array}$} \\
\cline { 3 - 5 } & Bajo & Medio & Alto \\
\cline { 2 - 5 } $\begin{array}{c}\text { Capital } \\
\text { Financiero }\end{array}$ & El Triángulo & & 3,0 & \\
\cline { 2 - 5 } & El Milagro & & 3,3 & \\
\cline { 2 - 5 } & La Favorita & & 2,8 & \\
\cline { 2 - 5 } & El Oso & & 3,3 & \\
\cline { 2 - 5 } & Vista Hermosal & & 3,0 & \\
\cline { 2 - 5 } & Vista Hermosall & & 3,8 & \\
\cline { 2 - 5 } & Elba Roja & & 3,8 & \\
\cline { 2 - 5 } & Lucitania & & 3,3 & \\
\cline { 2 - 5 } & Tres Esquinas & & 3,3 & \\
\hline
\end{tabular}

Fuente: Ios autores. 


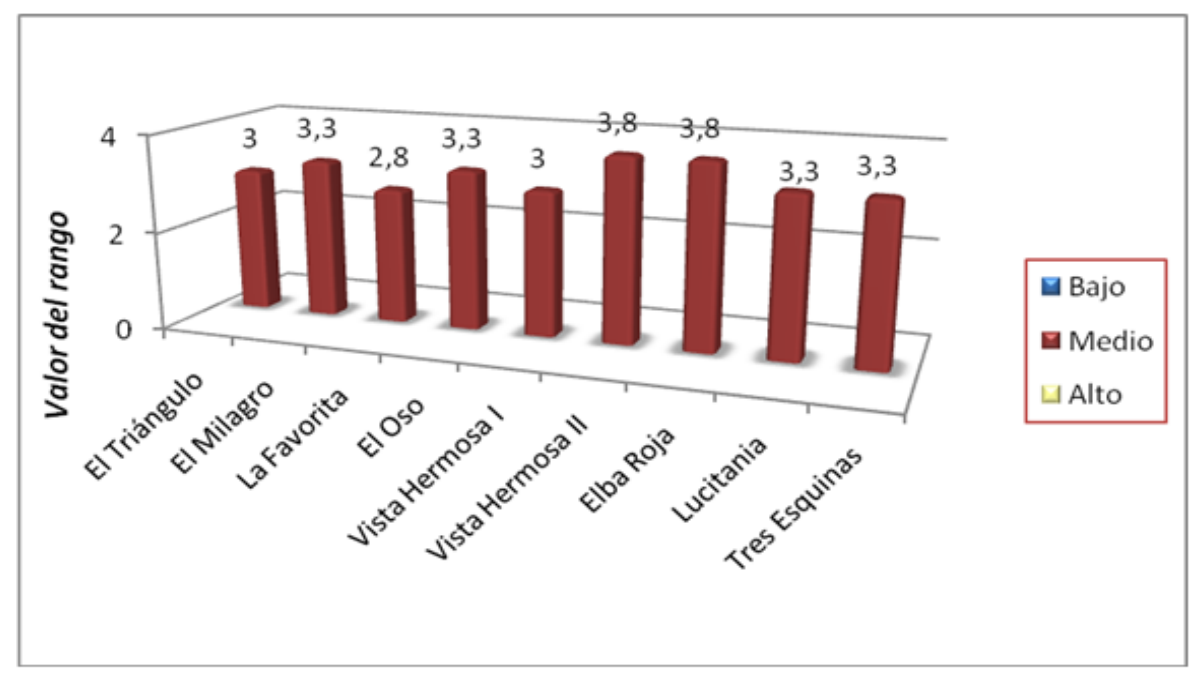

Fuente: Ios autores

Figura 6. Distribución del Capital Financiero para todos los hogares.

Los hogares de economía campesina de la FCV reportan bajos ingresos generados en forma directa por los predios, los demás ingresos deben suplirlos con otras actividades. La disponibilidad de efectivo se limita a cubrir solo sus necesidades básicas y a mantener el ciclo productivo; el 100\% de los hogares manifestó no tener la capacidad de ingresos suficiente para destinar al ahorro.

Según el informe del PNUD para Colombia 2011, cerca del 50\% de los ingresos de los campesinos de América Latina provienen de actividades distintas a la agrícola (PNUD, 2011).

En el proyecto "Viabilidad y reconstrucción del sector rural colombiano: Algunas bases para una propuesta para el desarrollo y convivencia pacífica" citando cifras de la Encuesta Nacional de Hogares Rurales del año 1997, se encontró que en ese mismo año el 56\% del empleo rural dependía de actividades agropecuarias y que años antes era del $61 \%$ lo que muestra la caída de empleos que se generaban por esta actividad (Corrales, 2002).

En general este grupo de hogares se caracteriza por realizar una combinación de actividades (trabajo poliactivo o multiempleo) para generar ingresos. Una fuente importante generadora de empleo es la actividad agrícola, siendo el renglón principal la producción de café, el cual se asocia al plátano, producto que genera mayor liquidez en los meses en que se espera la cosecha de café, también se presenta en asocio con algunos frutales como los cítricos, aguacate y cacao, los cuales son productos posicionados en el mercado; a diferencia del maíz, yuca, hortalizas, medicinales y aromáticas que en la mayoría de los casos se destinan a la dieta alimentaria familiar o al intercambio con vecinos, representando un ingreso no monetario. 
La actividad pecuaria sobresale en cuatro de los nueve hogares como opción para solventar necesidades de tipo económico y alimentario, esta junto con la agrícola, forman un sistema integrado de producción que ayuda a mantener la liquidez a partir de un ingreso básico para la subsistencia. Otras actividades que aportan a los ingresos familiares son la venta de mano de obra en fincas cercanas y actividades no agrícolas como el turismo rural, ayudas familiares, créditos y trabajos asalariados como contratos por fuera de la finca y la vereda para realizar labores de desyerba con guadañadora o contratos con entidades del sector agropecuario en labores puntuales y temporales; las ayudas de familiares son generadas por miembros de los hogares que han migrado de manera temporal o permanente a otras ciudades del país o al exterior.

De acuerdo con lo encontrado en el estudio cuatro hogares derivan sus ingresos de las actividades agrícolas y pecuarias, dos exclusivamente de la actividad agrícola, tres de la combinación de actividades donde además de las agropecuarias utilizan el turismo rural para complementar sus ingresos y en uno de estos hogares además se emplean por fuera del predio en entidades e instituciones del sector agropecuario como técnicos para complementar los ingresos del hogar.

Un dato importante que muestran los indicadores para el Capital Financiero es que el patrón de ingresos con el que cuentan los hogares se caracteriza por generar un efectivo mínimo para cubrir las necesidades básicas, ya que de este no queda un remanente para ser destinado al ahorro o a nuevas inversiones; esta situación se presenta como una debilidad o una restricción que impide el éxito de las demás estrategias de vida. La combinación o diversificación de actividades que realizan los hogares y su acceso al crédito es una ventaja para solventar la iliquidez en los meses de crisis económica.

\section{DISCUSIÓN}

La situación actual del sector cafetero, principal renglón de la economía de la comunidad que conforma la FCV, presenta una disminución a nivel nacional de hasta un $36 \%$ en el volumen de producción en los últimos cuatro años, atribuido principalmente al periodo invernal y al envejecimiento de los cultivos de café. Lo anterior, unido a la baja en los precios internos, como consecuencia de fenómenos macroeconómicos relacionados con la disminución del precio en la bolsa de Nueva York y la pérdida del poder adquisitivo del dólar, ha traído como consecuencia bajos precios y menor o nula rentabilidad de la actividad cafetera.

Esta situación ha influido notoriamente en la economía de las familias que conforman la Fundación, trayendo como consecuencia una merma en los ingresos y una disminución en la generación de empleo, lo que ha obligado a los miembros de los hogares a buscar otras fuentes de ingreso tanto en sus propias fincas como por fuera de ellas. 
Las fincas de la FCV cuentan con otros renglones agrícolas productivos a menor escala que no tienen un comercio ni un volumen de producción que se pueda equiparar a los ingresos que genera el café. El segundo renglón económico en importancia es el plátano, el cual sirve como ingreso adicional sobre todo en épocas donde no hay cosecha o la cosecha es muy baja, pero este solo renglón no alcanza a sustituir los ingresos que deja de generar el café.

La comunidad, a pesar de buscar alternativas de ingresos, le sigue apostando al cultivo del café como principal fuente generadora de los mismos, como lo evidencia su incorporación al programa de renovación de cafetales a través del Incentivo a la Capitalización Rural y la siembra de cultivos nuevos en los predios.

En el análisis de los Medios de Vida de la organización de base campesina, FCV, se encontró que los dos capitales con mayor valoración en sus indicadores fueron el Humano y el Físico. De igual manera, en este análisis se obtuvo una lista de comprobación que permitió clasificar las restricciones que impiden a las familias el éxito de las estrategias adoptadas y las relaciones que existen entre ellas. De acuerdo con los capitales evaluados, las principales estrategias y restricciones que despliegan los hogares son: 
Tabla 11. Estrategias y restricciones de medio de vida de los hogares de la FCV

\begin{tabular}{|c|c|c|}
\hline CAPITAL & $\begin{array}{c}\text { ESTRATEGIAS DE MEDIOS } \\
\text { DE VIDA }\end{array}$ & $\begin{array}{l}\text { RESTRICCIONES DE LAS } \\
\text { ESTRATEGIAS DE VIDA }\end{array}$ \\
\hline Humano & $\begin{array}{l}\text { Mano de obra. } \\
\text { Salud. } \\
\text { Población joven con grados } \\
\text { de escolaridad mayores a los } \\
\text { de los adultos. }\end{array}$ & $\begin{array}{l}\text { Nivel de escolaridad bajo en } \\
\text { educación formal y no formal de } \\
\text { los adultos y personas que se } \\
\text { encuentran en el rango de la vida } \\
\text { laboral activa. }\end{array}$ \\
\hline Social & $\begin{array}{l}\text { Organizacion interna de la } \\
\text { comunidad en grupos de } \\
\text { jóvenes, mujeres y familias } \\
\text { integrantes de la FCV. }\end{array}$ & $\begin{array}{l}\text { No existe regularidad en la } \\
\text { participación de los miembros del } \\
\text { hogar en las actividades } \\
\text { veredales. } \\
\text { Escaso beneficio obtenido por } \\
\text { programas y proyectos } \\
\text { institucionales realizados en la } \\
\text { vereda. }\end{array}$ \\
\hline Natural & $\begin{array}{l}\text { Suelo. } \\
\text { Manejo ecológico } \\
\text { sustentable del suelo. } \\
\text { Biodiversidad. }\end{array}$ & $\begin{array}{l}\text { Limitado acceso al recurso agua } \\
\text { por parte de algunos hogares. } \\
\text { Escaso conocimiento de prácticas } \\
\text { agroecológicas y uso inadecuado } \\
\text { de productos de sintesis química. }\end{array}$ \\
\hline Físico & $\begin{array}{l}\text { Acceso a tierra - tenencia de } \\
\text { la tierra. } \\
\text { Infraestructura privada. }\end{array}$ & $\begin{array}{l}\text { Falta de mantenimiento ala } \\
\text { infraestructura de beneficio del } \\
\text { café. } \\
\text { Infraestructura pública deficiente } \\
\text { sobre todo en vias de acceso. }\end{array}$ \\
\hline Financiero & $\begin{array}{l}\text { Tngresos provenientes de } \\
\text { miembros del hogar en } \\
\text { actividades agricolas, } \\
\text { pecuarias y combinación de } \\
\text { actividades. } \\
\text { Acceso a créditos bancarios. }\end{array}$ & $\begin{array}{l}\text { Falta de efectivo. } \\
\text { Escasa capacidad de ahorro. } \\
\text { Acceso a créditos bancarios con } \\
\text { dificultades para dar cumplimiento } \\
\text { a los pagos. }\end{array}$ \\
\hline
\end{tabular}

A parte de las restricciones, los hogares de la FCV mostraron evidencias importantes en el logro de medios de vida como estrategia y/o tácticas de supervivencia ante la crisis de la caficultura de los últimos años. Dentro de la estructura de medios de vida de la FCV se identificaron activos que están relacionados con cada uno de los cinco capitales y los 17 indicadores evaluados.

Un medio de vida importante que refleja el capital humano es la disponibilidad que tienen los hogares campesinos de mano de obra familiar para aportar a las labores productivas y el conocimiento tradicional que han heredado de sus padres y abuelos, esto les permite desarrollar actividades familiares $\mathrm{y} / \mathrm{o}$ comunitarias en pro de las necesidades de cada hogar o de la vereda, sin tener que contratar mano de obra externa: realizan mingas, convites y mano cambiada en jornadas de trabajo colectivo para ayudarse mutuamente y cumplir metas o propósitos comunes. La no contratación de mano de obra externa representa un menor valor de los costos de la producción agropecuaria y la posibilidad de sacar adelante proyectos comunes. 
Es importante resaltar que, si bien el indicador de educación formal es bajo por el nivel que alcanzaron los adultos de la comunidad, la gente joven, adolescentes y niños, se encuentra estudiando en la escuela de la vereda o en instituciones educativas de veredas vecinas buscando elevar su nivel educativo como una estrategia para afrontar las dificultades propias de la vida en el campo; este activo tiene una doble condición, pues si bien es cierto conlleva a mejorar las condiciones de vida de los miembros jóvenes de las familias, también resulta ser una vía para la migración, pues la mayoría considera que hay que estudiar "para buscar trabajo por fuera de la finca y no tener que seguir con las condiciones que se viven en ella"; en este sentido, la educación no representa una oportunidad para mantenerse en la finca, por el contrario es una forma de poder salir para mejorar su nivel de vida.

El segundo capital de la FCV que presenta activos de medios de vida es el Capital Físico. El mayor activo que presenta es la tenencia de la tierra ya que todas las familias son propietarias, gracias a ello han podido ser beneficiarias de programas como el de la reconstrucción después del terremoto ocurrido en 1999 y han tenido acceso a créditos bancarios a los que han acudido para desarrollar proyectos productivos y recapitalizarse para llevar a cabo inversiones; visto de esta manera, se considera un activo, sin embargo, un porcentaje importante de las familias manifiesta que la difícil situación del mercado de los productos agropecuarios les ha impedido dar continuidad a los proyectos en los que se han involucrado, ocasionando con ello dificultad para cumplir con las cuotas bancarias, lo que ha puesto en riesgo sus fincas ya que uno de los requisitos que exigen este tipo de créditos es la hipoteca; en algunos casos se han visto obligados a renegociar las deudas y, en otros, han optado por vender las fincas para poder pagar el crédito y no perderlo todo.

Una situación que referencian los hogares es que muchas familias que ya que no pertenecen a la FCV han migrado por falta de condiciones económicas para permanecer en el campo y otras lo han hecho huyendo de riesgos por situaciones de orden público.

El turismo ha sido un renglón económico que han venido operando los hogares de la FCV durante los dos últimos años como medio para obtener ingresos, por ello, una de las actividades que realizan es la atención a giras de estudiantes de la región y/o grupos de personas con el fin de dar a conocer su proceso organizativo y de desarrollo rural endógeno; esto ha derivado en un cambio de razón social de la FCV que pasó a llamarse Corporación Mixta Consejo Comunitario. A raíz de esto, los habitantes de la vereda han realizado adecuaciones a sus viviendas con el fin de alojar a los potenciales visitantes, han diseñado recorridos en sus fincas, senderos ecológicos y paisajísticos, elaboran artesanías y muestran un paquete de actividades rurales que comparten con los visitantes con el fin de mostrar sus costumbres, su trabajo, el medio en el que viven y el territorio en que habitan. 
Otro activo importante que presenta este capital es que por tratarse de fincas ubicadas en zona cafetera, el estado en el que se encuentra la infraestructura productiva es bueno, sin embargo está subutilizado a raíz de la crisis del café, y en algunos casos requiere mantenimiento para poder funcionar eficientemente.

Los capitales Humano y Físico representan estrategias de supervivencia muy importantes para los hogares de la FCV como son: disponibilidad de mano de obra, acceso a salud y elevación de los niveles de educación en la gente joven, tenencia de la tierra, viviendas adecuadas para la habitación e infraestructura productiva en buenas condiciones.

Las estrategias de vida que se encuentran asociadas a estos dos capitales les ha facilitado a las familias redefinir algunas de las actividades productivas tradicionales, por ejemplo, optar por el turismo rural, actividad que les permite, sin dejar de lado la producción agropecuaria, poder complementar los ingresos. Se destaca de la apuesta por el turismo rural un interés comunitario de permanecer en el campo, además se observa que los cambios en las actividades económicas de las familias campesinas de la FCV] siempre han estado acompañados de valores, tradiciones y normas que rigen su vida en comunidad y su cultura, lo cual les ha significado la cohesión grupal y el acompañamiento solidario que representa una característica significativa de las agriculturas campesinas (Cowan y Schneider, 2008).

El hecho de que las familias campesinas opten por estrategias de diversificación agrícola, va de la mano con:

[...] la racionalidad local en la cual las estrategias de vida o medios de supervivencia, configurados con base en el conocimiento de los ecosistemas y la cultura, constituyen un recurso fundamental para la reproducción de la unidad familiar y sus sistemas de producción. Una amplia gama de estrategias le permite al campesino tal reproducción, pero, el uso de mano de obra familiar, el conocimiento que tienen sobre el medio y la integración de múltiples actividades para asegurar el ingreso, constituyen los pilares fundamentales de las estrategias de vida de sociedades campesinas. (Mora-Delgado, 2008)

No obstante estas fortalezas, en muchas ocasiones no son suficientes para superar las graves dificultades que se les presentan, en tanto la gran mayoría son de carácter estructural y no están al alcance de su control y/o manejo, por ejemplo, el acceso a la zona rural por falta de carreteras o puentes, la falta de voluntad política para construir o mejorar estas situaciones o las restricciones que se les presentan, por ejemplo, al prestar servicios turísticos de manera informal, entre otras.

En la FCV los capitales Natural y Financiero presentaron comportamientos similares, ubicándose en rangos medios. Esto 
se da gracias al buen uso que en general han hecho de los recursos agua, suelo y biodiversidad. La diversificación productiva es una de sus principales fortalezas pues les permite la combinación de actividades agrícolas y pecuarias, junto a otras como la autosuficiencia alimentaria y/o la prestación de servicios turísticos, esta situación representa algunas características del concepto de multifuncionalidad de la agricultura.

Entendida de acuerdo con Atance y Tió (2000, pp. 30-31) como:

[...] la incorporación a la función tradicional de producción de materias primas y alimentos de todas aquellas funciones realizadas por la agricultura que van más allá de ésta y por las cuales el agricultor no obtiene un bien intercambiable en los mercados. [...] el reconocimiento de que la agricultura realiza una serie de funciones que exceden ampliamente la mera producción de materias primas y alimentos.

Que para el caso de la FCV no termina por consolidarse, pues aunque los hogares procuran hacer un uso adecuado del suelo y llevan a cabo algunas prácticas de conservación, una de sus principales limitaciones es el poco conocimiento que tienen sobre prácticas agroecológicas y la escasa planificación que realizan de las labores del predio.

El Capital Social por su parte, presenta valores diferentes entre un hogar y otro, ubicándose la mayoría en un rango medio. Las diferencias las marca principalmente el número de integrantes del hogar que participa en las reuniones sociales, ya que en algunos casos lo hace solo una persona, y en otros todos sus integrantes.

Aunque los hogares participan y se articulan a otros grupos de la región, se plantea como debilidad el escaso beneficio obtenido de políticas, programas y/o proyectos institucionales. Los campesinos pertenecientes a la FCV revelan que, en ocasiones, la asociatividad a la que los han inducido desde este tipo de programas, en la gran mayoría de las casos, ha sido de carácter funcional o instrumental, es decir, con el fin de captar recursos provenientes de un programa o proyecto pero en últimas no les han contribuido al fortalecimiento de la organización comunitaria y al desarrollo de procesos endógenos y autogestionarios.

Los resultados de la autogestión comunitaria los han obtenido gracias a la cohesión y a los lazos de solidaridad que han desarrollado por iniciativa propia y no precisamente porque las estructuras institucionales -tipo asociaciones de productoreshayan sido determinantes; con respecto a esto los campesinos refieren que en la vereda se llegaron a tener una gran cantidad de organizaciones que lo que hicieron fue diluir las iniciativas locales y hacer perder la confianza en las instituciones, pues los horarios de las reuniones y los compromisos que debían adquirir no les dejaban tiempo para realizar las labores agrícolas. 
Una fortaleza que se destaca a nivel de este capital es el alto nivel de organización social y la eficaz red de comunicación alcanzada entre las familias, pues todos discuten, opinan, y comparten ideas relacionadas con las problemáticas y los procesos que les atañen; gracias a esto las familias han podido, bajo esquemas de trabajo comunitario, colaborativo y solidario, sacar adelante proyectos como el de turismo rural que se ha constituido en una estrategia económica por la que han optado para obtener ingresos y poder atender la manutención de las familias y los compromisos bancarios que poseen.

Esta característica particular de las economías campesinas refleja como los valores, el vínculo con la tierra, con las semillas, con sus antepasados, con el lugar mismo, son elementos fundamentales de la persistencia campesina que configuran su identidad, la cual puede ser mucho más fuerte que cualquier racionalidad económica, por esto, más que un modo de producción, el campesinado debe considerarse como un modo de vida. (Mora-Delgado, 2008)

En cuanto al Capital Financiero, los pequeños productores de economía campesina acceden a este capital con muchas limitaciones, principalmente porque aunque el portafolio de actividades les permite generar ingresos, estos no son suficientes para dar continuidad al proceso productivo y suplir algunas de las necesidades básicas, la falta de efectivo no les permite realizar inversiones y limita en cierta medida la posibilidad de acceso a otros activos; los escasos ingresos generados por la actividad agrícola les impide dar cumplimiento a los compromisos crediticios poniendo en riesgo su permanencia en las fincas y obligándolos, en algunas ocasiones, a vender la finca y migrar hacia la ciudad capital o municipios cercanos.

Los indicadores relacionados con el Capital Financiero: Efectivo, Ahorro, Ingresos y Crédito dan cuenta de la difícil situación económica por la que atraviesan las familias de la FCV, explicable por la falta de rentabilidad de las actividades productivas, el escaso acceso a mercados y la irregularidad de los precios; además de la poca disponibilidad de efectivo para suplir las necesidades básicas y los compromisos bancarios; pese a esto, las familias han utilizado los medios de vida relacionados con cada capital para diversificar sus ingresos y el acceso a ellos, lo cual en su conjunto, constituye una estrategia de supervivencia no solo a nivel del hogar, sino también de toda la comunidad.

La producción agropecuaria combinada con el turismo rural, la venta de artesanías, los servicios ambientales (no valorados económica pero sí social y culturalmente), el acceso (aunque escaso) a beneficios de programas y proyectos, la tenencia de la tierra, los lazos de solidaridad, el trabajo grupal, el cubrimiento en salud, la disponibilidad de mano de obra, la infraestructura productiva y doméstica y el interés por conservar y potenciar la bio y agrodiversidad, son activos que muestran la capacidad de 
las familias de la FCV de desplegar una estructura de estrategias de vida que les ha permitido, aun en condiciones difíciles, permanecer en la vereda y no migrar a la ciudad.

Los activos de los hogares de la FCV, convertidos en estrategias de reproducción social, tienen como característica principal, que hacen parte de las acciones sobre las cuales las familias tienen control social e incidencia comunitaria; por el contrario, las restricciones como el bajo nivel de escolaridad, el escaso acceso a beneficios de programas y proyectos institucionales, la falta de infraestructura pública, la falta de efectivo y ahorro y la falta de mercados, son aspectos que provienen del contexto que rodea a las familias $y$, en buena medida, al resorte de la institucionalidad estatal en relación con las políticas y programas orientados al sector agropecuario. Cabe resaltar aquí las consecuencias de la actual crisis de la caficultura y del sector agropecuario en general; sin embargo, se acentúa en este análisis, cómo a pesar de las condiciones tan adversas, las familias desarrollan mecanismos de resistencia que hacen más viable su permanencia en el campo.

Las familias campesinas resuelven, por la vía de la acción colectiva y la diversificación, sus posibilidades de subsistencia en el campo, y a pesar de no contar con recursos ni condiciones adecuadas, inciden desde su accionar colectivo en "fenómenos sociales tan complejos como la pobreza, la distribución de los ingresos, la productividad agrícola, la conservación del medio ambiente y las relaciones de género" (Ellis, 1999).

Las estrategias de diversificación que se encontraron en las familias de la FCV se enmarcan principalmente en estrategias educativas, definidas como aquellas en las que las familias buscan la transmisión de los valores familiares, solidarios y campesinos entre las generaciones desde la esfera de la acción solidaria y el trabajo en equipo; las familias han puesto en juego también estrategias de inversión económica orientadas a la perpetuación del capital económico en sus diferentes formas, siendo la más representativa, el poder conservar la propiedad de la tierra y continuar la actividad agropecuaria. Sobresale en el análisis, una fuerte apuesta por "acciones tendientes a conservar y a aumentar el capital de reconocimiento; a favorecer la reproducción de los esquemas de percepción y apreciación más favorables al grupo familiar" y a la estructura tradicional campesina (Cowan y Schheider, 2008).

Las familias integrantes de la FCV son un caso representativo de cómo:

[...] la agricultura familiar ha demostrado una notable capacidad de convivencia con entornos socio-económicos hostiles, marcados por el desprestigio ideológico y por el desamparo político. Su fuente principal de resistencia puede ser explicada por el hecho de que adopta una racionalidad técnica y económica que considera el largo plazo, ya que sus sistemas productivos 
se orientan tanto a la atención de las necesidades de la familia, como a la conservación de las potencialidades productivas del medio natural. En este sentido, la organización de los procesos productivos en las unidades familiares es realizada [como se observa en la FCV] con una lógica que conlleva el principio de la auto-regeneración de los sistemas socio-técnicos. El equilibrio entre la producción económica y la reproducción social en los sistemas agrícolas familiares, permite que se mantengan aun en condiciones económicas adversas, ya que pueden continuar operando con bajas tasas de remuneración monetaria, siempre y cuando se conserven altas tasas endógenas de reproducción biológica, técnica y social. (Petersen, 2003, p. 64)

En el análisis de los medios de vida de la FCV se observa un ambiente y un contexto altamente vulnerable, en tanto que las familias solo han logrado resistir la crisis del sector agropecuario gracias a su propia gestión, sin que se observen políticas y/o programas en los que se "hayan realizado esfuerzos por vincular, de manera sistémica, las múltiples actividades en los que participan los hogares rurales, con las políticas de reducción de la pobreza" (Ellis, 1999).

La diversificación de estrategias de vida de los agricultores de la FCV, en un contexto de crisis del sector agropecuario en general y de la producción cafetera en particular, no es un fenómeno ajeno a la situación de los agricultores campesinos del siglo XXI, por el contrario, representa una maniobra de supervivencia.

Que de acuerdo con Pretty (1995), Gliessman (1998) y Rosset (1999) indica que:

[...] a pesar del fenecimiento augurado [sobre su paulatina desaparición] como resultado de la modernización e industrialización, vaticinio compartido por los economistas clásicos, los campesinos están lejos de desaparecer en el siglo XX. Por el contrario, su persistencia ha sido objeto de análisis, y sus sistemas de producción se presentan como opciones potencialmente más equitativas y eco amigables que la modernización agrícola convencional.

El caso de las familias campesinas de la FCV ilustra, de manera alarmante, cómo en la zona cafetera colombiana los hogares rurales se dedican cada vez más a otras actividades generadoras de ingresos no agrícolas y dependen de carteras más diversificadas en las cuales la participación de la actividad agropecuaria ha disminuido considerablemente. Ellis (1999) plantea que "mientras más diversa es la cartera de ingresos, mejor la situación económica que tiene el hogar rural", sin embargo, el trasfondo de esta situación debe analizarse desde la 
disminución de los ingresos por cuenta de la actividad agropecuaria, esto cuestiona fuertemente la vinculación de los campesinos a la producción alimentaria y la posibilidad de continuidad en el medio rural, lo cual revierte en el fenómeno de proletarización rural.

Otra mirada es que la diversificación de ingresos en las economías campesinas se debe a la lógica económica de las unidades familiares.

La persistencia campesina es evidente, debido a la flexibilidad de la producción ante los embates del mercado y la sociedad en general. Dicha flexibilidad, que le permite al sistema de producción campesino reacomodarse a las diferentes situaciones de la dinámica del mercado, está determinada por su funcionamiento basado en el uso de mano de obra familiar. En su mayoría, los jornales, sino todos, son empleados en las diferentes actividades productivas y aportados por los diferentes miembros de la familia. (Berdegue y Larrain, 1988); Ellis, 2000).

Esto le permite a la unidad familiar una cierta "elasticidad" ante los altibajos de los precios pagados por los productos y ante las pérdidas ocasionadas por las fluctuaciones del clima. Si los precios bajan y, por tanto, el ingreso familiar disminuye, la familia tendrá que aumentar su trabajo para compensar con volumen la productividad disminuida (Lehmann, 1986, citado por Mora-Delgado, 2008); ocasionalmente los campesinos venden mano de obra o se emplean en actividades no agrícolas, como estrategia para movilizar ingresos monetarios desde el exterior hacia su unidad familiar. (Ibídem, 2000)

La capacidad de las familias campesinas de ampliar la diversificación de las fuentes de ingreso ha sido vista como una estrategia de supervivencia y una forma de resistencia a abandonar la actividad agropecuaria, sin embargo, el concepto amerita un cuidadoso análisis ya que en los debates que ha generado se presenta como una justificación y legitimación a problemáticas tales como la pobreza, la desocupación rural, la falta de empleo, la carencia de políticas públicas y el fomento de las agriculturas y los mercados campesinos, además de la inclusión de beneficios para los mismos. A este respecto se debe entender que la multifuncionalidad de la agricultura es un aspecto de orden económico que tiene implicaciones sobre la política agraria y que hace parte de la Agenda 2000 acordada en 1999 por la PAC -Política Agrícola Comunitaria Europea- que contempla la MFA como uno de sus objetivos y justificaciones esenciales.

De acuerdo con Atance y Tió (2000, p. 33): 
[...] el concepto de multifuncionalidad surge en un momento histórico en el que existe "peligro" para la actividad agraria, ya que la obtención de productos agrarios deja de ser un objetivo social deseable, al poderse importar más baratos de otros países, por lo que en caso de abandonarse la actividad productiva pudiera perderse "conjuntamente" las externalidades positivas.

Así mismo Brass, 1991 y Petersen, 2003 estiman que:

Así, los campesinos, vistos como individuos con un énfasis puesto en su persistencia en una sociedad, representan un grupo social que está subordinado a otros sectores de la sociedad moderna que los obliga a efectuar cambios en su dinámica solamente para persistir en medio de la sociedad y para satisfacer sus necesidades básicas

\section{CONCLUSIONES}

Se logró la identificación de actividades o estrategias que implementan las familias de la FCV con el fin de generar ingresos y mejores condiciones de vida, así como las interacciones que se establecen entre estas y fenómenos sociales tales como la pobreza, el origen y distribución de los ingresos, las políticas para la diversificación, diversificación vs. agricultura, organización social, educación y acceso a mercados. Los resultados del estudio muestran que los capitales de mayor valoración fueron el Humano con una media de 4,16 y el Físico con una media de 4,04. Los capitales con menor valoración fueron el Social con una media de 3,09 y el Financiero con una media de 3,29. El Capital Natural se ubica en un rango medio con respecto a los demás de 3,56 .

La producción agropecuaria combinada con el turismo rural, la venta de artesanías, los servicios ambientales (no valorados económica pero sí social y culturalmente), el acceso (aunque escaso) a beneficios de programas y proyectos, la tenencia de la tierra, los lazos de solidaridad, el trabajo grupal, el cubrimiento en salud, la disponibilidad de mano de obra, la infraestructura productiva y doméstica y el interés por conservar y potenciar la bio y agrodiversidad son activos que muestran la capacidad de las familias de la FCV de desplegar una estructura de estrategias de vida que les ha permitido, aun en condiciones difíciles, permanecer en la vereda y no migrar a la ciudad.

Las actividades o estrategias de medios de vida de las familias que componen la FCV, identificadas en el estudio fueron: mano de obra, salud y población joven con grados de escolaridad mayores a la de los adultos, relacionadas con el Capital Humano. El Capital Social muestra una organización interna de la comunidad en grupos de jóvenes, mujeres y familias; el Capital 
Natural muestra como activos el manejo ecológico y sustentable del suelo y un incremento de la biodiversidad; el Capital Físico presenta acceso a tierra y tenencia de la misma, así como una infraestructura privada en buenas condiciones; el Capital Financiero presenta ingresos provenientes de miembros del hogar en actividades agrícolas, pecuarias y combinación de las mismas, así como también acceso a créditos bancarios.

La restricciones que presentan las estrategias de medios de vida de los hogares de la FCV son las siguientes: en cuanto al Capital Humano: un nivel de escolaridad bajo en educación formal y no formal de los adultos y personas que se encuentran en un rango de la vida laboral activa, falta de regularidad en la participación de los miembros del hogar en actividades veredales y escaso beneficio obtenido por programas y proyectos institucionales, ambos relacionados en el Capital Social. El Capital Natural presenta, en algunos hogares, limitado acceso al recurso agua, escaso conocimiento de prácticas agroecológicas y uso inadecuado de productos de síntesis química; el Capital Físico muestra, como restricciones, la falta de mantenimiento a la infraestructura de beneficio del café y una infraestructura pública deficiente, sobre todo en vías de acceso; por último, las restricciones del Capital Financiero tienen que ver con la falta de efectivo, escasa capacidad de ahorro e incumplimiento de los pagos de créditos bancarios.

Las estrategias de diversificación que se encontraron en las familias de la FCV se enmarcan principalmente en estrategias educativas, definidas como aquellas en las que las familias buscan la transmisión de los valores familiares, solidarios y campesinos entre las generaciones desde la esfera de la acción solidaria y el trabajo en equipo; las familias han puesto en juego, también, estrategias de inversión económica orientadas a la perpetuación del capital económico en sus diferentes formas, siendo la más representativa el poder conservar la propiedad de la tierra y continuar la actividad agropecuaria.

El caso de las familias campesinas de la FCV ilustra, de manera alarmante, cómo en la zona cafetera colombiana los hogares rurales se dedican cada vez más a actividades generadoras de ingresos no agrícolas y dependen de carteras más diversificadas en las cuales la participación de la actividad agropecuaria ha disminuido considerablemente; el trasfondo de esta situación debe analizarse desde la disminución de los ingresos por cuenta de la actividad agropecuaria, lo cual cuestiona fuertemente la vinculación de los campesinos a la producción alimentaria y la posibilidad de continuidad en el medio rural, lo que revierte en el fenómeno de proletarización rural.

La experiencia de la comunidad FCV les permitió expresar que, aunque la pluriactividad ha sido una estrategia de vida que ha generado un aporte económico importante a los hogares, la actividad agrícola es la que mayor aporte hace al conjunto de la economía campesina y sigue siendo de gran relevancia como fuente de ingresos para ellos. 
El estudio de los medios de vida de la FCV muestra que la problemática rural que afecta principalmente a los pequeños productores campesinos, no debe enfocarse exclusivamente desde una perspectiva económico productiva, esta situación tiene un trasfondo sociocultural y político que abarca comportamientos relacionados con los efectos de los procesos de globalización, los cuales generan nuevas percepciones sobre las dinámicas de estos grupos, su forma de desarrollar mecanismos de sobrevivencia y las estrategias de adaptación al cambio. Una característica importante de esta adaptación es la diversificación de las estrategias de vida de las comunidades rurales, las cuales se encaminan a la implementación de la pluriactividad y la multifuncionalidad de las fuentes generadoras de ingresos, y sobre todo al uso óptimo que puedan hacer de sus activos o capitales ya que de estos depende la sostenibilidad en el tiempo de las estrategias de vida, para hacer frente a las situaciones cambiantes y reducir la vulnerabilidad.

El reconocer el contexto de vida en que actúan permite, a los hogares campesinos, entender qué es un medio de vida, cómo ellos hacen uso de este y cómo lo transforman a través de dinámicas comunitarias emergentes; aun así, estos escenarios necesitan la implementación de metodologías participativas que enfaticen la importancia de la inclusión de la población en procesos generadores de desarrollo rural que respondan en mayor grado a las necesidades de las comunidades rurales menos favorecidas, reconociéndolos como actores capaces de involucrarse en la búsqueda de soluciones y generar sus propias oportunidades de autonomía y dignidad.

\section{REFERENCIAS}

- Atance Muñiz, I. y Tió Saralegui, C. (2000). La multifuncionalidad de la agricultura: Aspectos económicos e implicaciones sobre la política agraria. Revista de Estudios Agrosociales y Pesqueros, 189, 29-48.

- Berdegue, J. y Larrain, B. (1988). Cómo trabajan los campesinos. Cali: CELATER.

- Brass, T. (1991). Moral Economist, subalterns, New Social Movements and the (re) emergence of a (post) modernized peasant. Journal of Peasant Studies, 18(2), 214-242.

- Corrales Roa, E. (2002). Viabilidad y reconstrucción del sector rural colombiano. Elementos de política para el sector rural propuestas por ONG ambientalistas. (inédito).

- Cowan Ros, C. y Schneider, S. (2008). Estrategias Campesinas de Reproducción Social: El caso de las tierras altas Jujeñas, Argentina. Revista Internacional de sociología (Ris), 66(50), 163185.

- DFID - Department for International Development-. (1999). Hojas orientativas sobre los medios de vida sostenibles. Recuperado de http://community.eldis.org/.59c21877/SP-GS1.pdf

- Ellis, F. (1999). La Diversidad de las Estrategias de vida rural en los países en Desarrollo: Evidencias e Implicaciones para las políticas. Red Internacional de Métodos de Investigación de 
Sistemas de Producción. Recuperado de http://www.rimisp.org/index.php/index.php

- . (2000). Rural livelihoods and diversity in development countries. Nueva York, US: Oxford University Press.

- Federación Nacional de Cafeteros -Federacafé-. (1993-1997). Encuesta Nacional Cafetera. Bogotá: Autor.

- Flora, C., Flora J. y Fey, S. (2004). Rural communities: legacy and change. USA: Westview Press.

- Fonseca, L.A. (2003). Colombia: Escenario social, económico e institucional de la actual crisis cafetera. Oficina CEPAL en Colombia. (inédito).

- Gliessman, S.R. (1998). Agroecology: Ecological Processes in Sustainable Agriculture. Chelsea, MI, US: Ann Arbor Pres.

- Gobernación del Quindío. (2009). Informe Agropecuario año 2009. Evaluaciones Agropecuarias Departamento del Quindío. Armenia, Quindío: Autor.

- Instituto Colombiano de la Reforma Agraria - Ministerio de Agricultura de Colombia. (1996). Resolución 041 del 24 de Septiembre de 1996 de la oficina de Formalización y Legislación Agraria. Bogotá: Autor.

- Lehmann, D. (1986). Two Paths of Agrarian Capitalism, or a Critic of Chayanovian Marxism. Comparative Studies in Society and History, 28, 601-627. Recuperado de http:77dx.org/10.1017/S0010417500014122

- Miranda, A.B. (2003). Capital social, institucionalidad y territorios el caso de Centroamérica. 2a edición. IICA: Nicaragua y Costa Rica.

- Mora-Delgado, J. (2008). Persistencia, conocimiento local y estrategias de vida en sociedades campesinas. Revista de Estudios Sociales, Universidad de los Andes, 122-133. Recuperado de http://res.uniandes.edu.co/view.php/430/view.php

- Pretty, J. (995). Regenerating Agriculture: Policies and Practice for Sustentability and Self- Reliance. London: Earthscan Publications.

- Petersen, P. (2003). Evaluando la sustentabilidad: estudios de caso sobre impactos de innovaciones agroecológicas en la agricultura familiar de diferentes países latinoamericanos. LEISA, Revista de Agroecología - ocho estudios de caso, Edición Especial, 64-67.

- Rosset, P. (1999). The Multiple Functions and Benefits of small Farms Agriculture: In The Context Global Trade of Negotiations. Food First Policy, 4. Oakland: The Institute for Food and Development Policy.

- Stoin, D. y Donovan, J. (2010). Articulación del mundo campesino con el mercado - Integración de Enfoques de Medios de Vida y Cadena Productiva. VI Semana Científica del Catie, 14-16. Recuperado http://orton.catie.ac.cr/repdoc/A0292E/PDF/2.PDF

1. Agrónoma UNISARC. ymalope@gmail.com

2. Mag. en Desarrollo Regional y Planificación del Territorio. Docente asistente, Facultad de Ciencias Agrícolas de UNISARC. carlos.bedoya@unisarc.edu.co 
3. Mag. en Sociedades Rurales. Docente asociada, Facultad de Ciencias Administrativas y de Desarrollo Rural de UNISARC. agroecologia@unisarc.edu.co

4. Palabras de Jorge Mario Rojas Morales, presidente de la Junta Directiva de la Fundación Consejo Veredal, 2012.

5. Manejo Integrado de Plagas y Enfermedades.

Para citar este artículo: Cárdenas Grajales, G.I., Bedoya Patiño, C.G. y Marín López, Y. (2014). Estrategias de adaptación y medios de vida de las familias integrantes de la Fundación Consejo Veredal -FCV-, municipio de Calarcá, Quindío. Revista Luna Azul, 41 , 201-239 . Recuperado de http://lunazul.ucaldas.edu.co/index.php?option=content\&tas k=view\&id=1063 